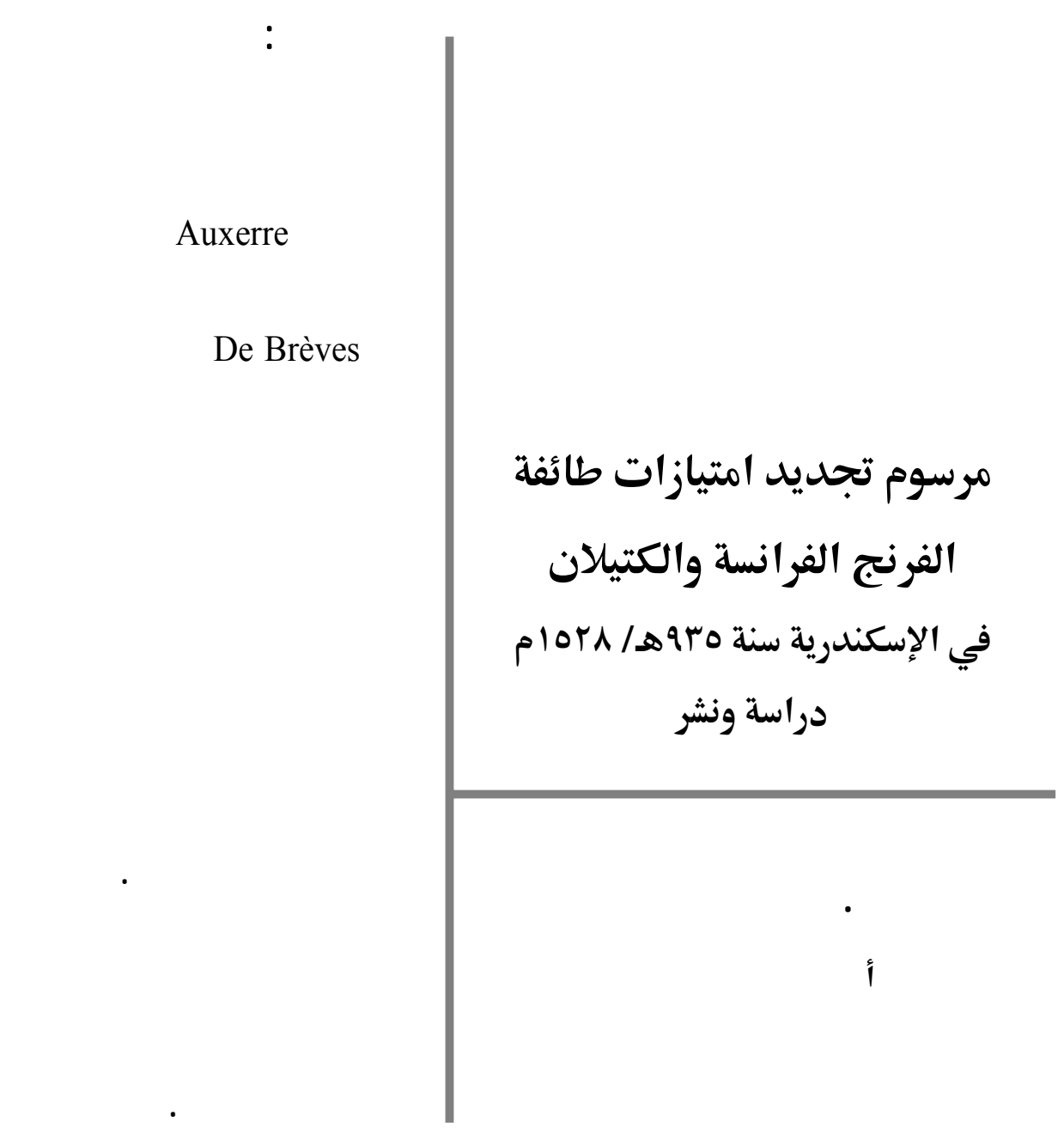


71

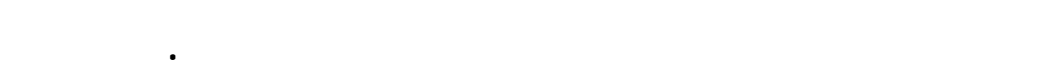

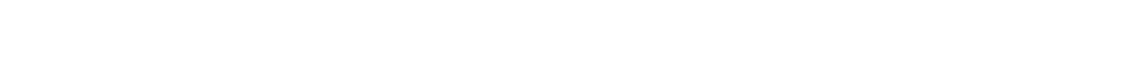

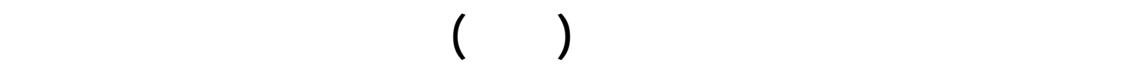

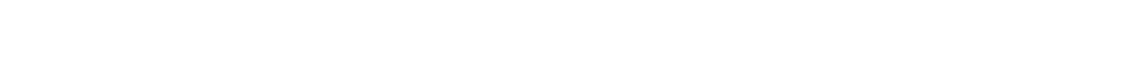

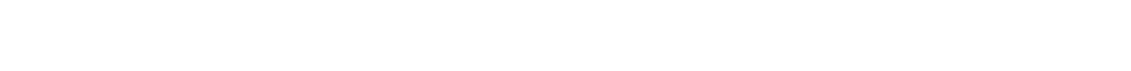

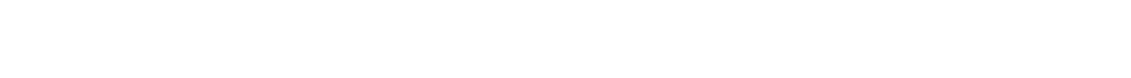

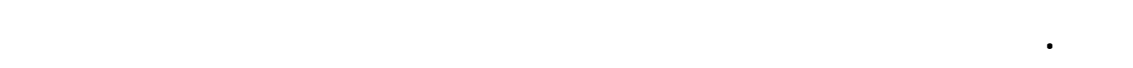

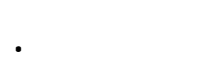
أولاًَ- نشأة القنصلية والطائفة الفرنسية بالإسكندرية:

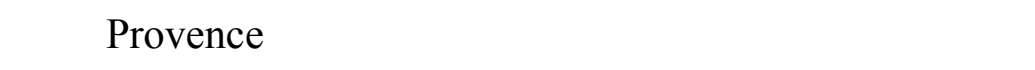

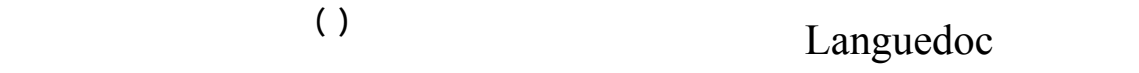

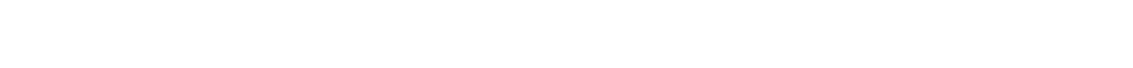

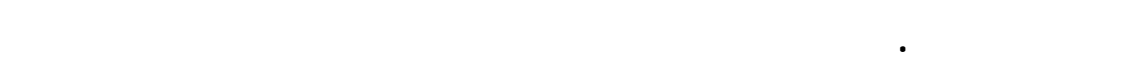

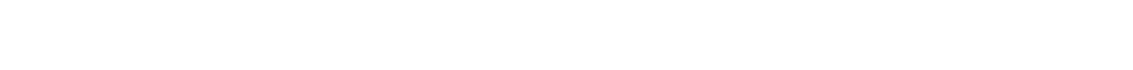

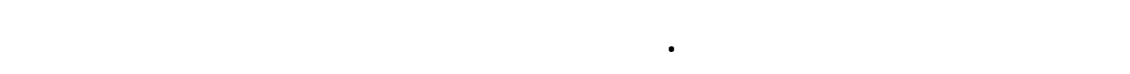

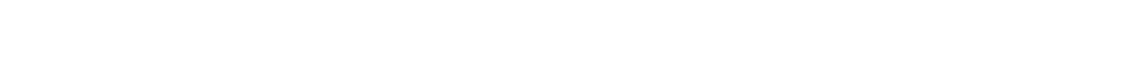

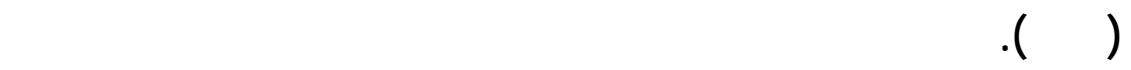

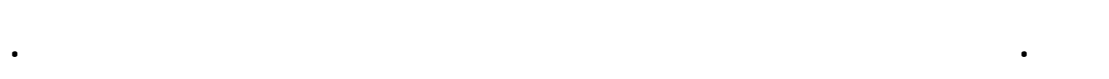

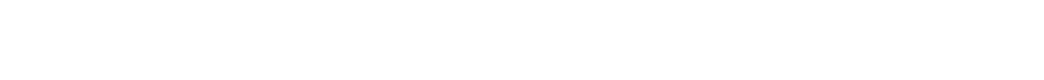

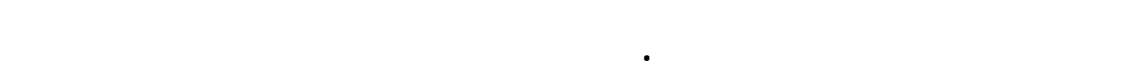

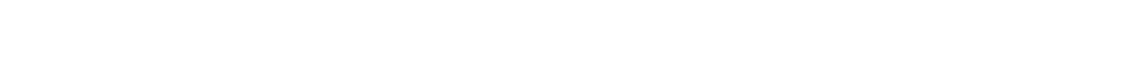

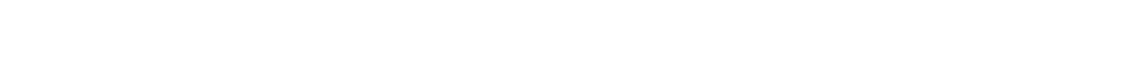




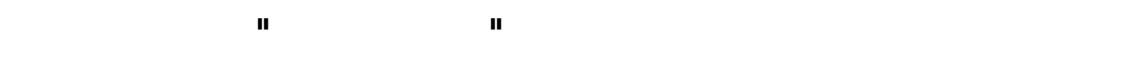

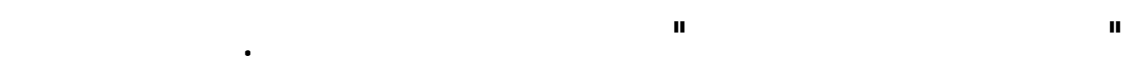

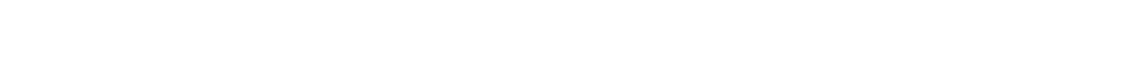

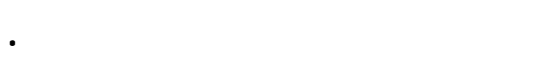

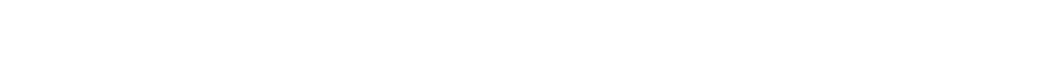

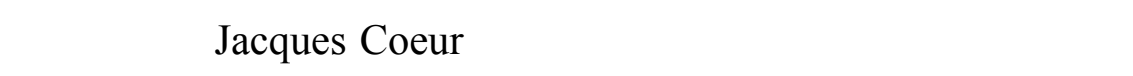

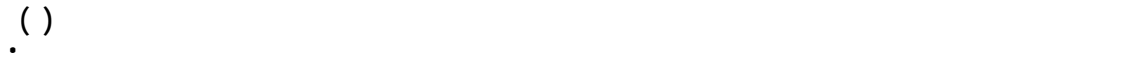

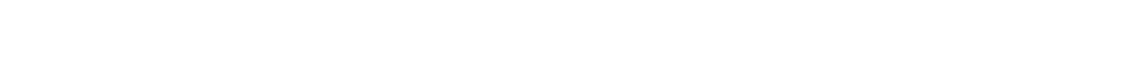

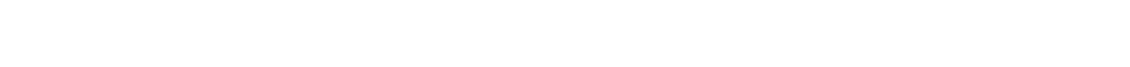

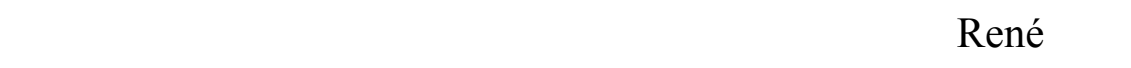

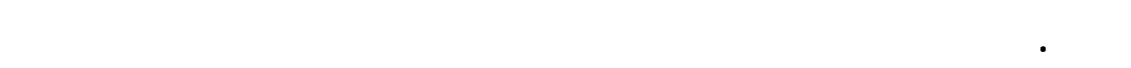

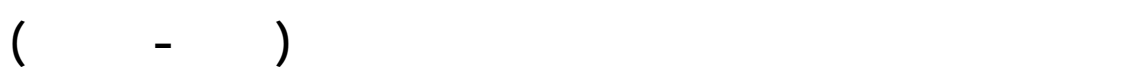

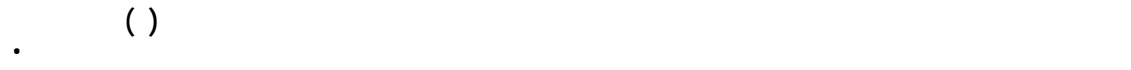

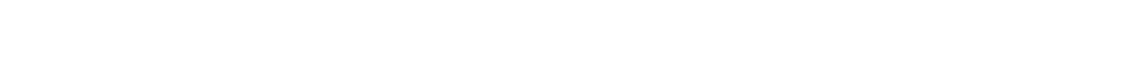

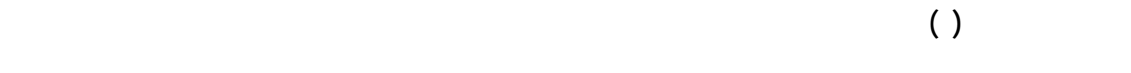

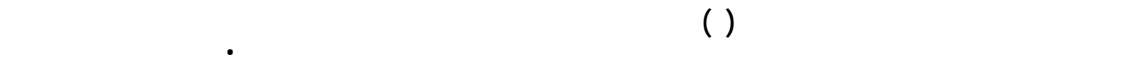

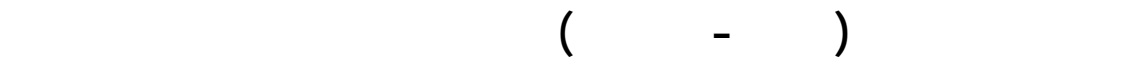

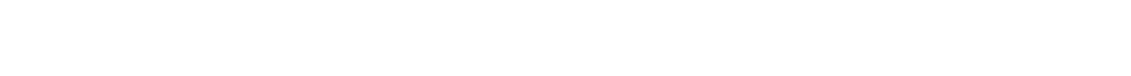

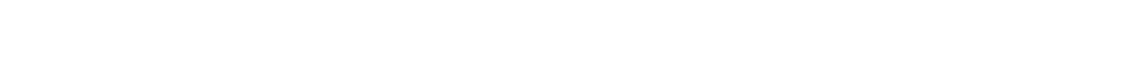

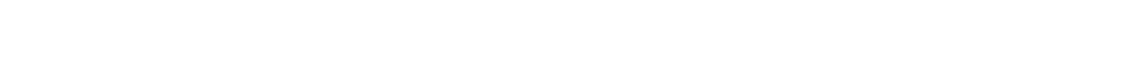

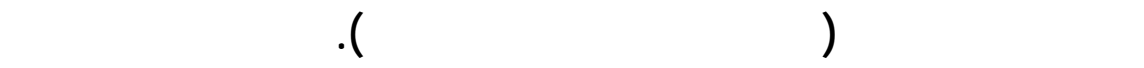

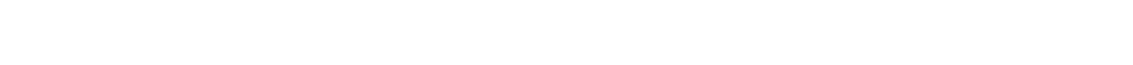
في كي مي بالرتس (1) Felipe De Parets 
د. Th

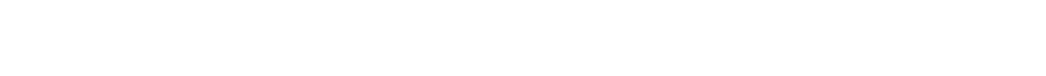

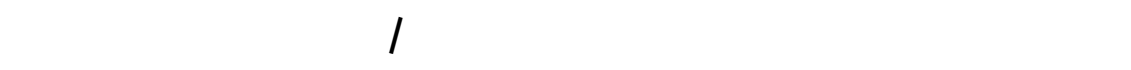

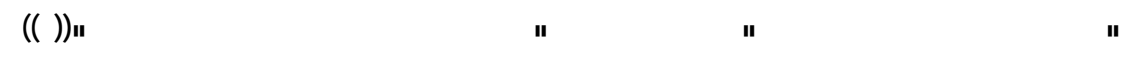

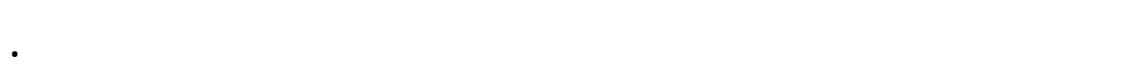

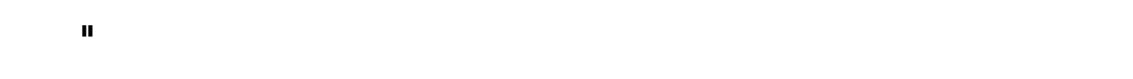

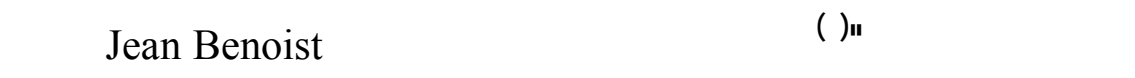

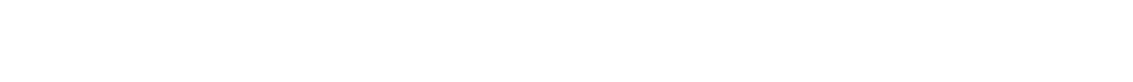

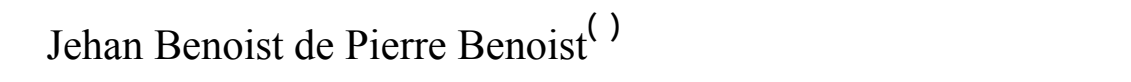
ولا هو فهه الشضص الفي ذكرة وئة مؤرة بالثلن من في النهقسة

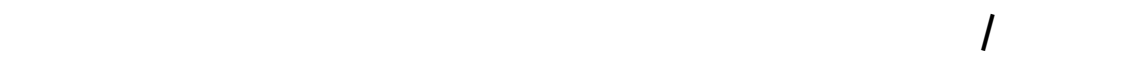

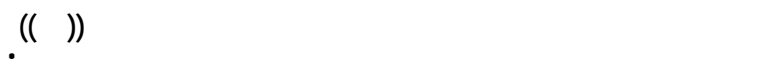
ثانيًا- العثمانيون كقوة أوروبية ومتوسطية جديدة:

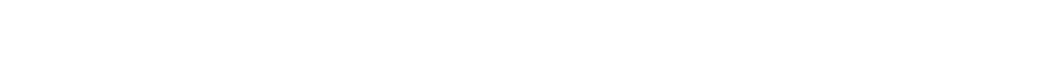

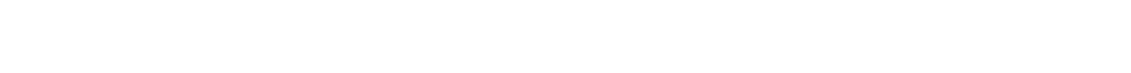

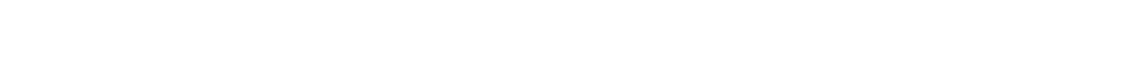

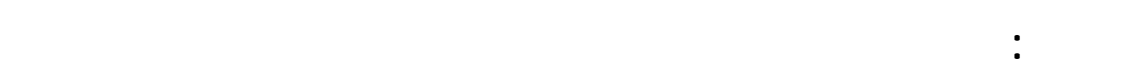

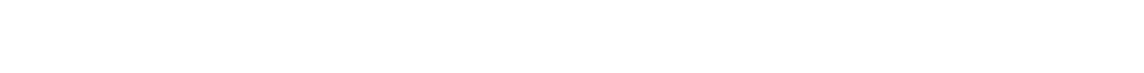

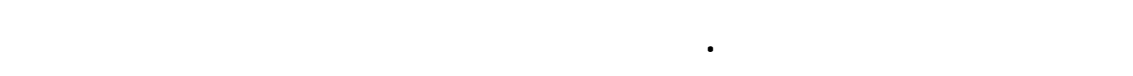

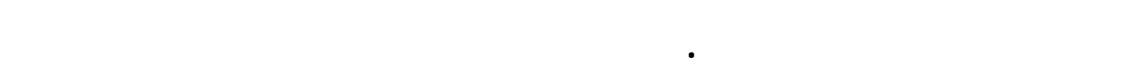

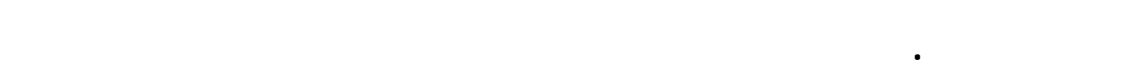

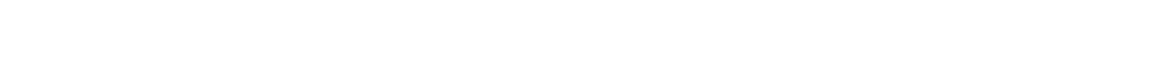

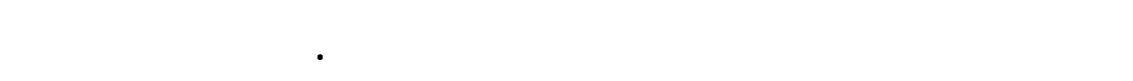




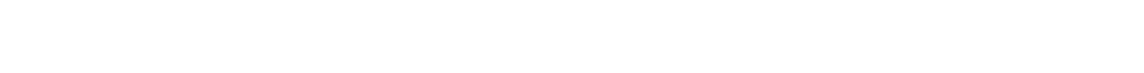

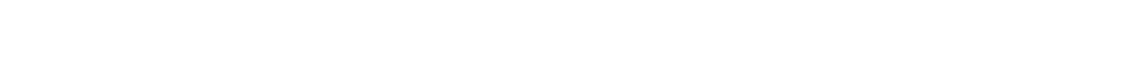

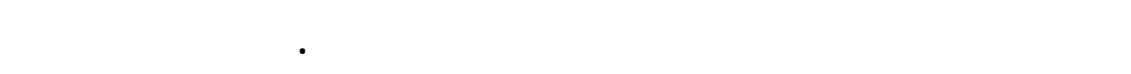
1 ـ 10 كل يلائه عل المود الثرقيةقوة جديةهي الأسرة المفوة.

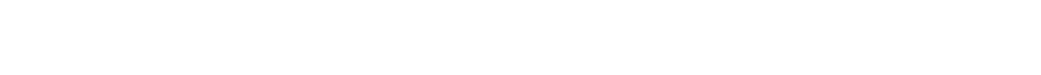

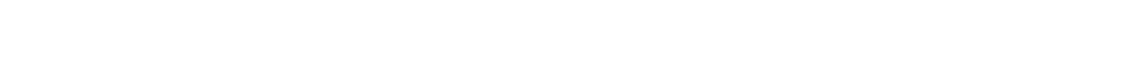

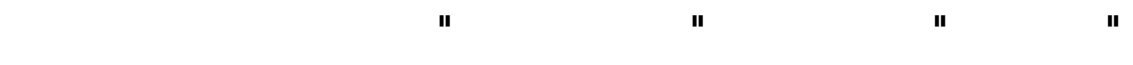

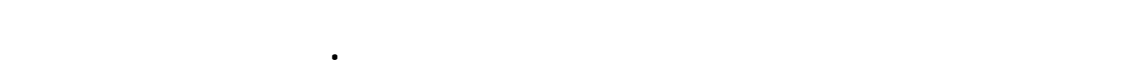

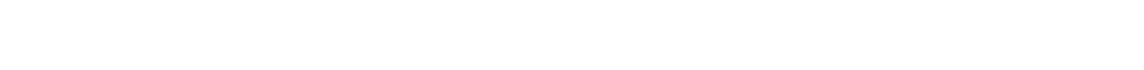

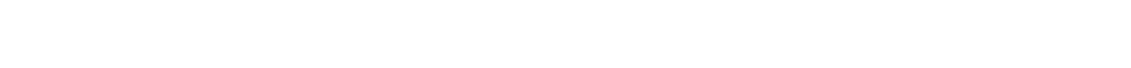

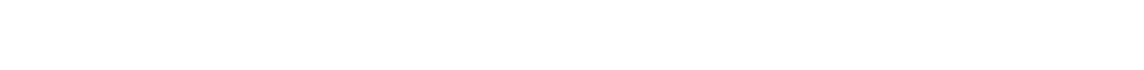

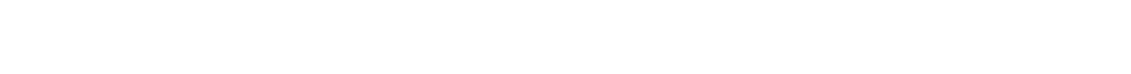

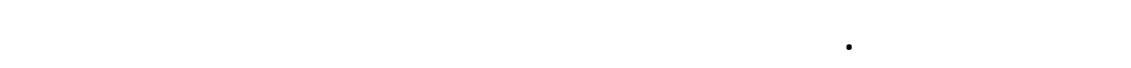

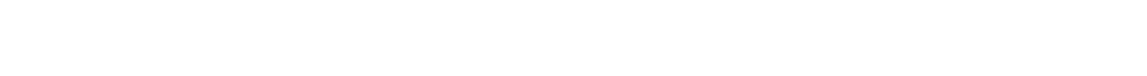

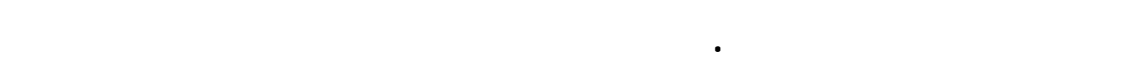

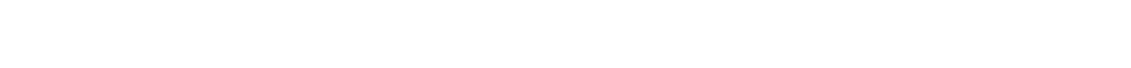

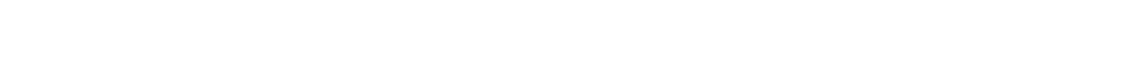

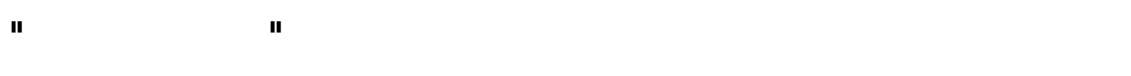

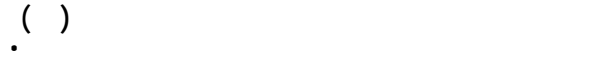

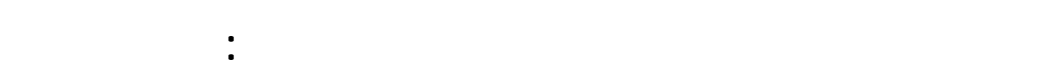

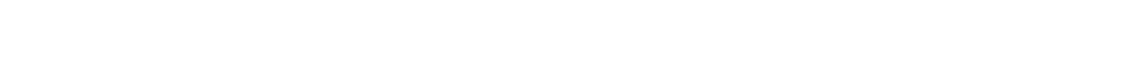

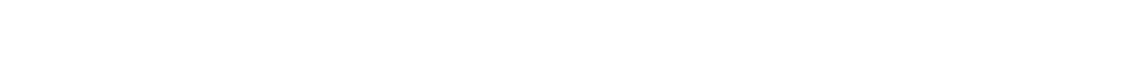

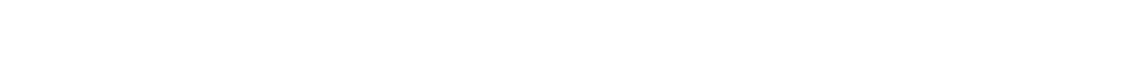




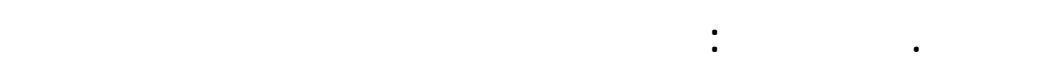

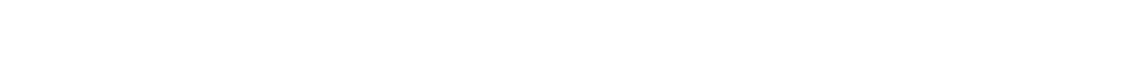

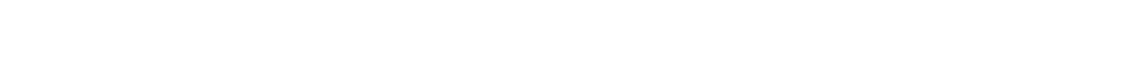

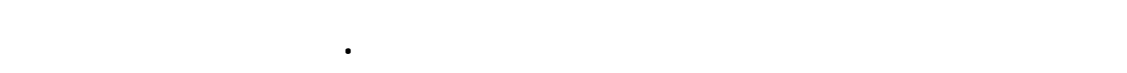

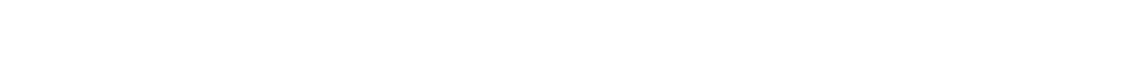

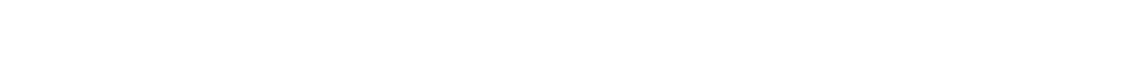

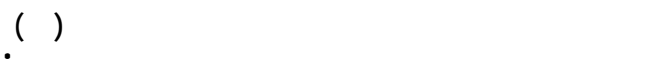

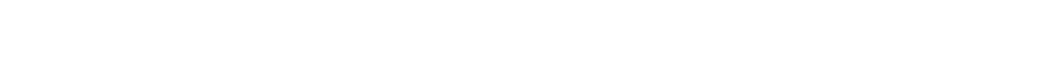

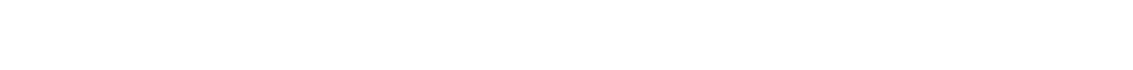

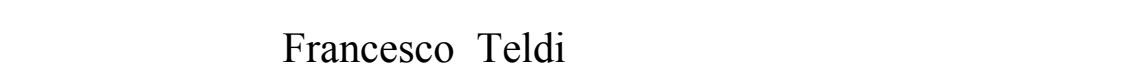

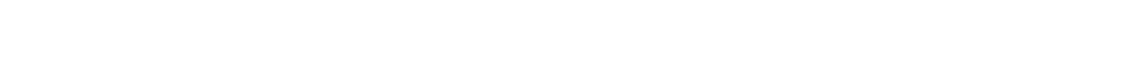

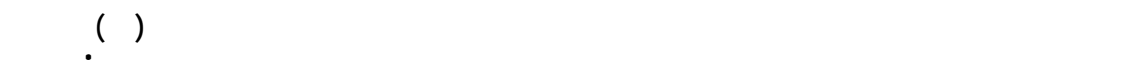

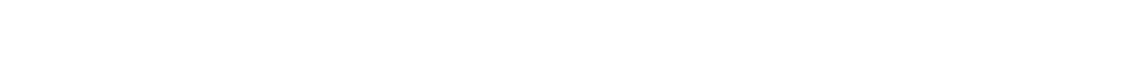

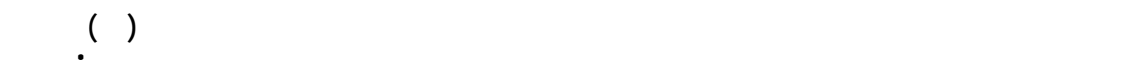

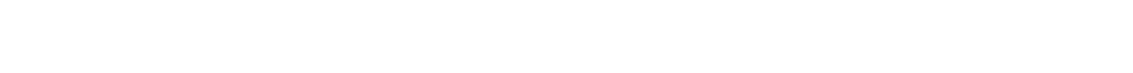

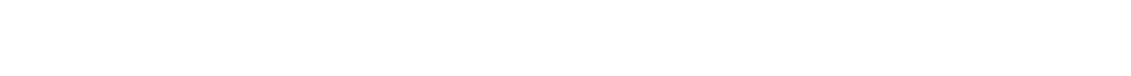

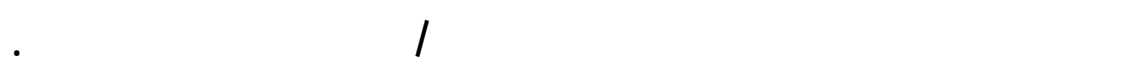

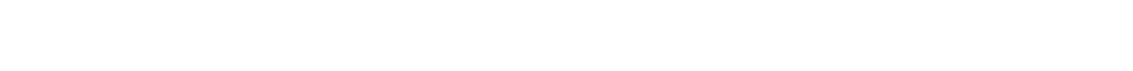

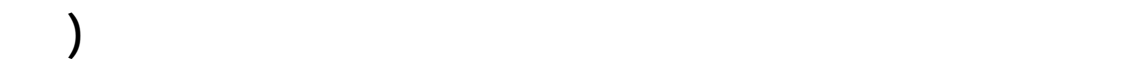

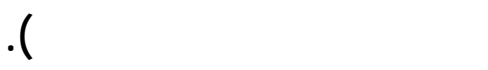

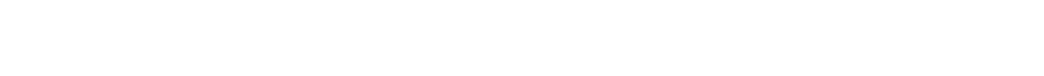

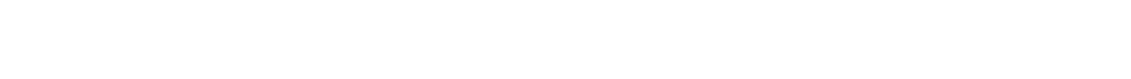

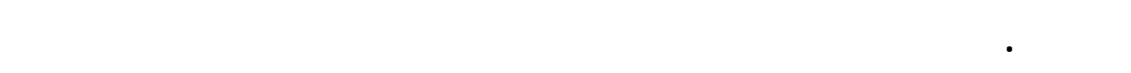


لصزنلة (لمد المانر -rו - r )

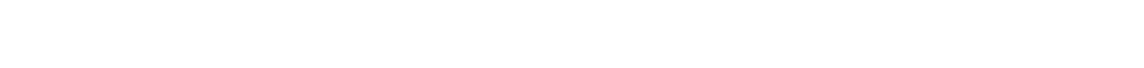

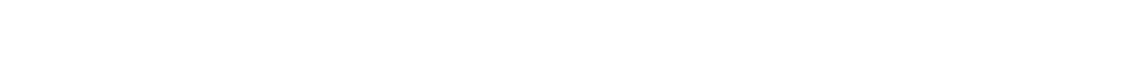

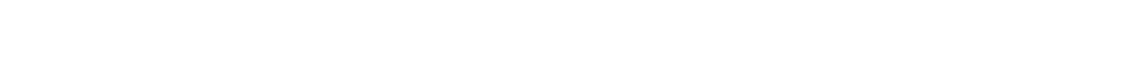

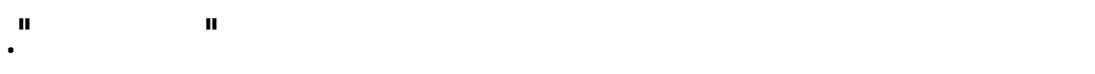

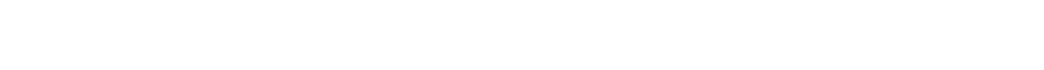

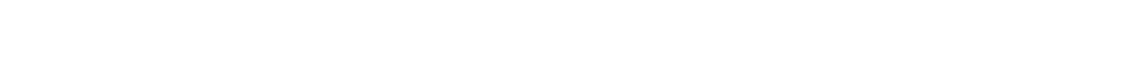

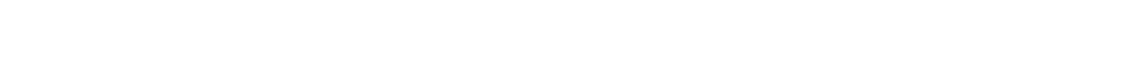

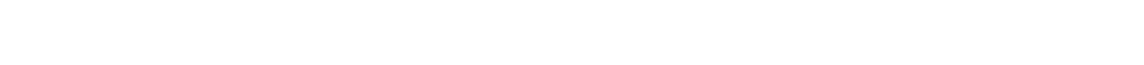

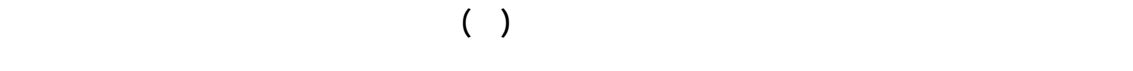

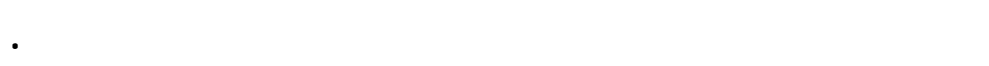

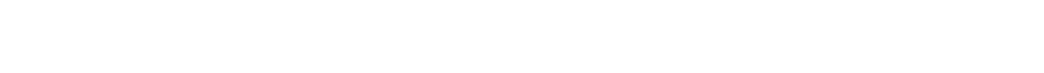

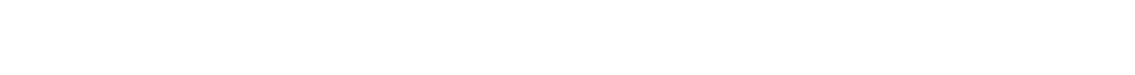

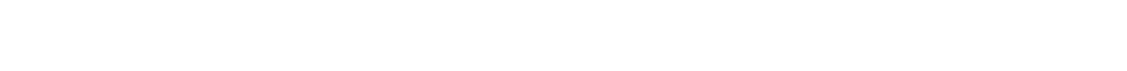

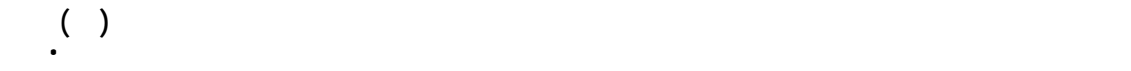

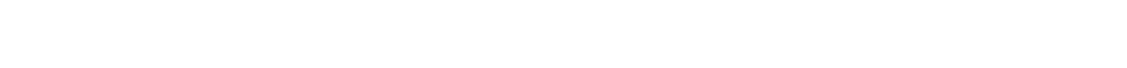

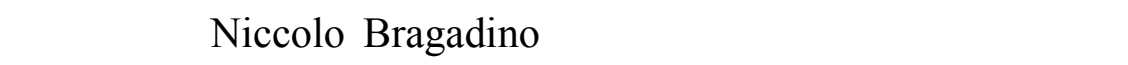

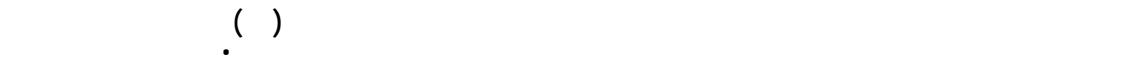

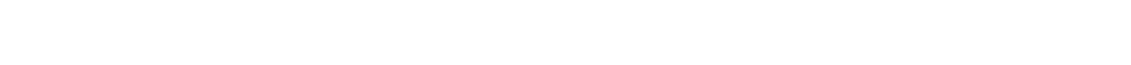

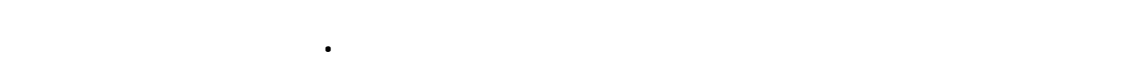

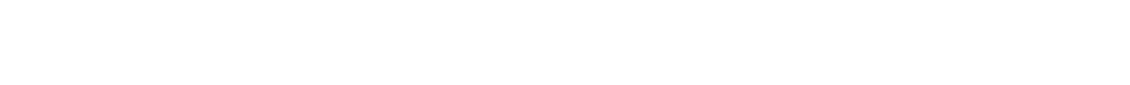

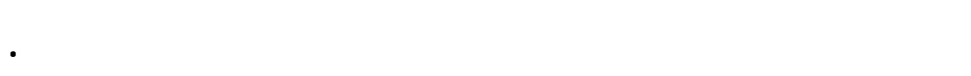

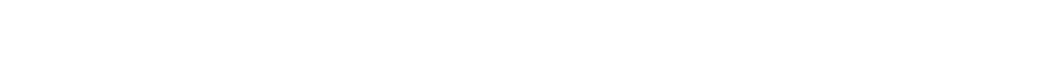

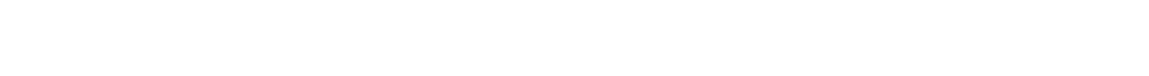


S. VT

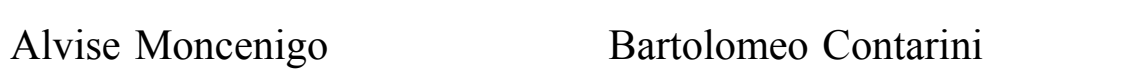

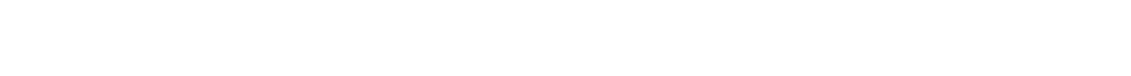

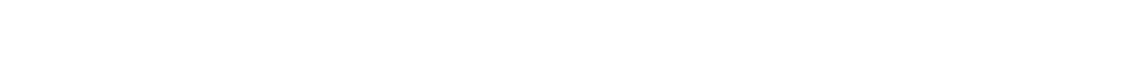

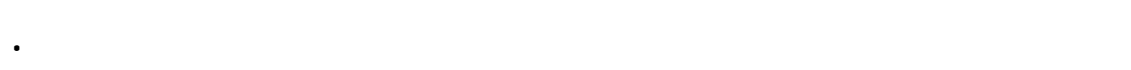

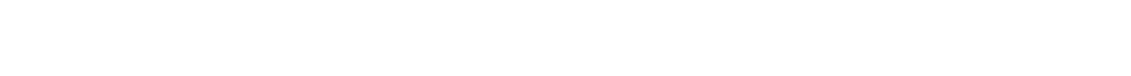

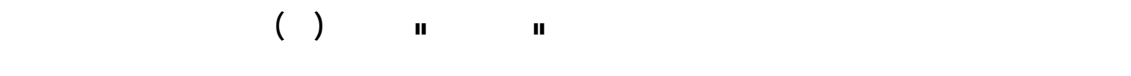

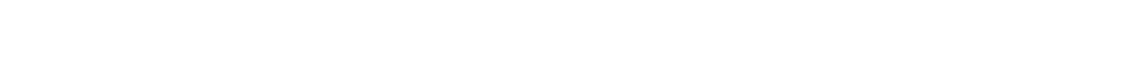

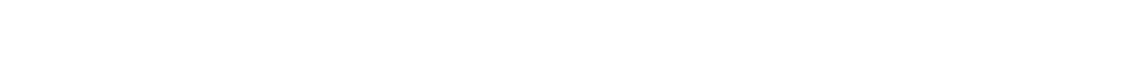
المطالنسليم.

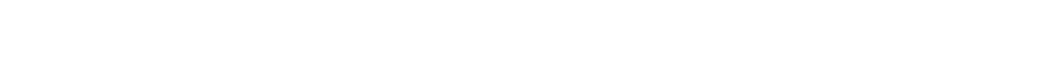

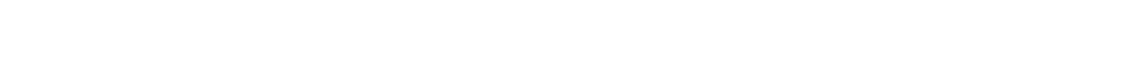

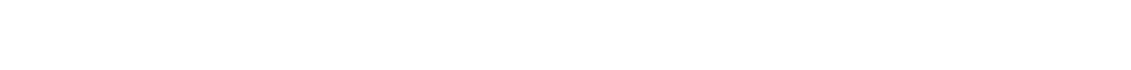

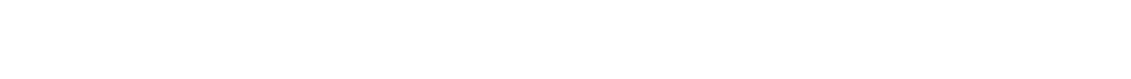

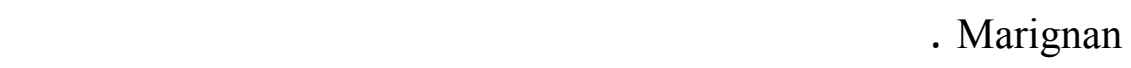

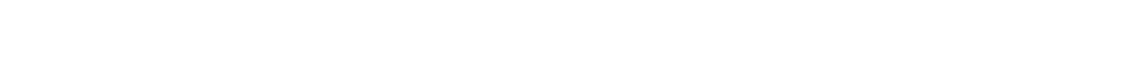

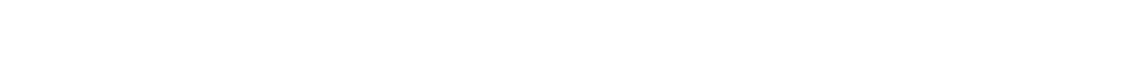

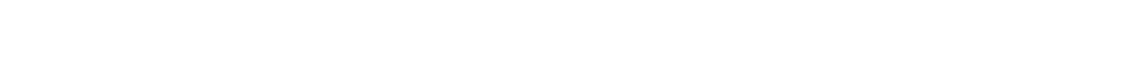

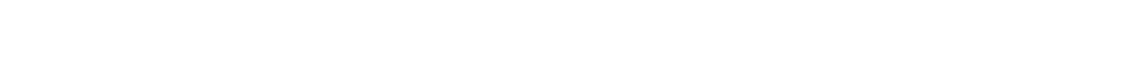

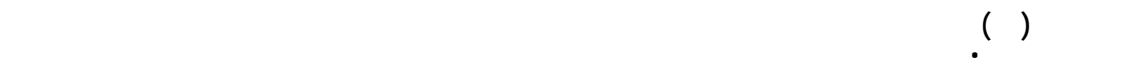

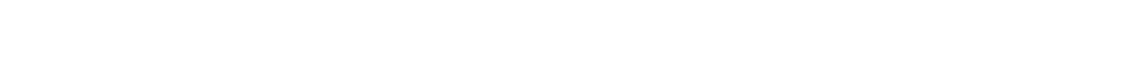

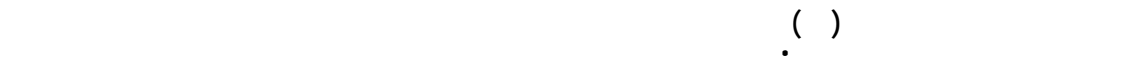


nw

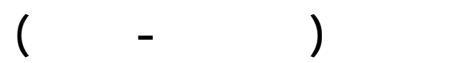

ثالثًا- التقارب بين فرنسا والدولة العثمانية وتجديد الامتيازات:

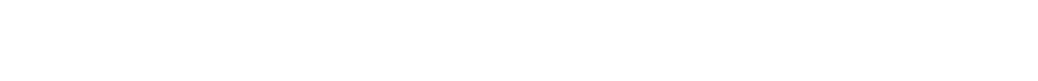

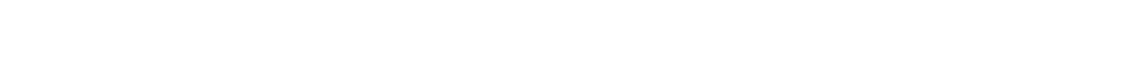

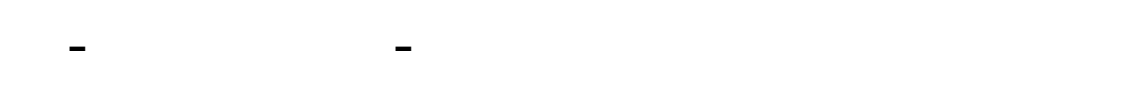

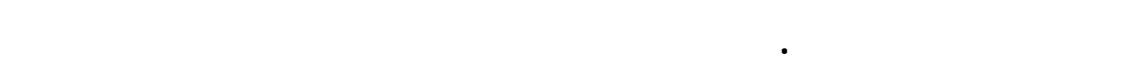

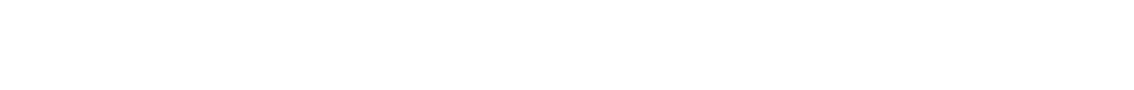

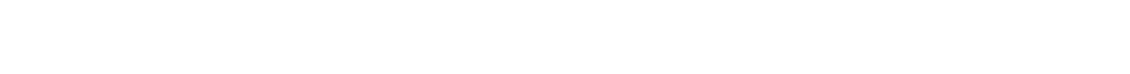

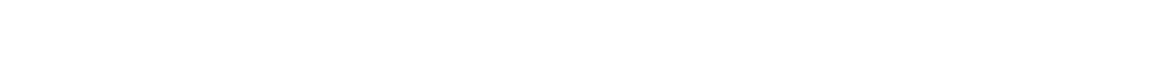

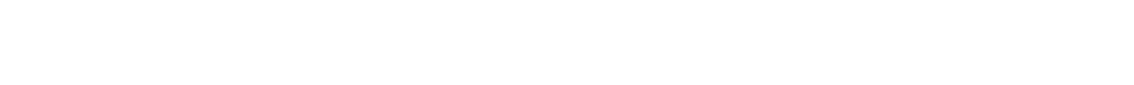

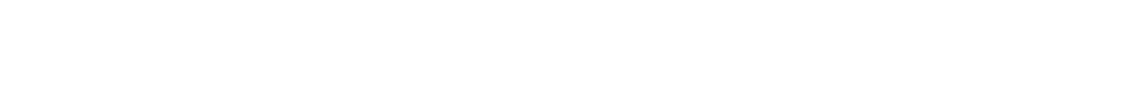

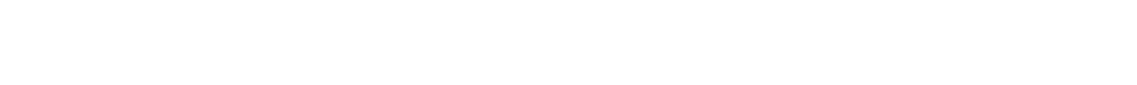

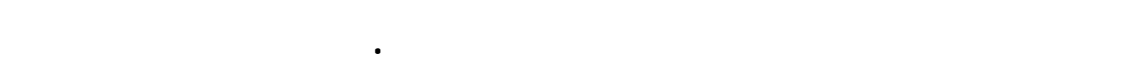

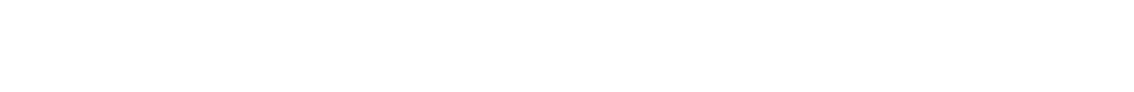
مسطوا Souise de Savoie

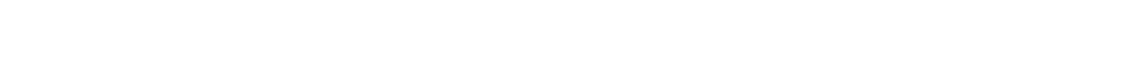

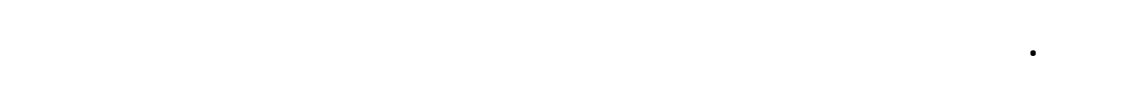

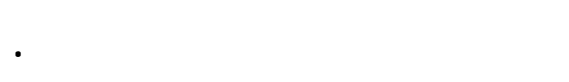

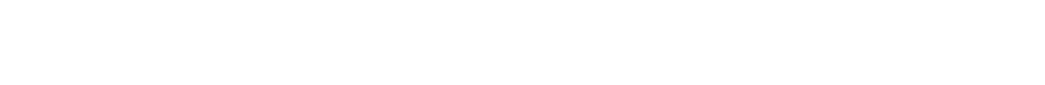

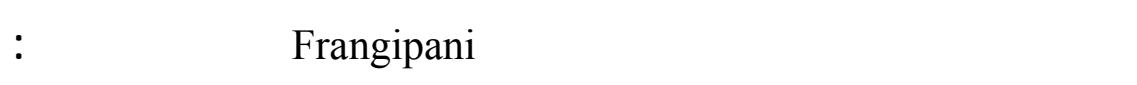

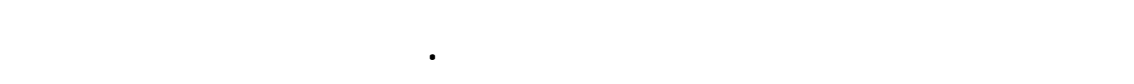

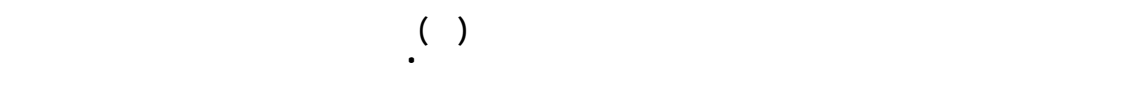

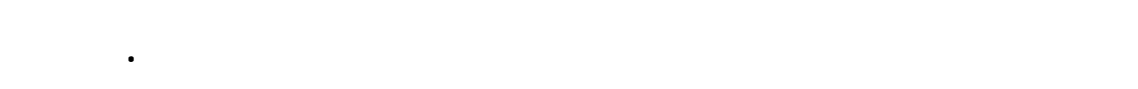


VE

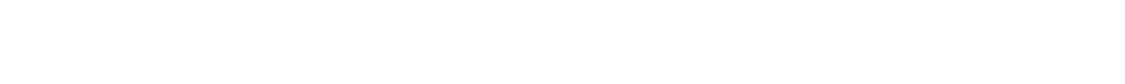
علالت لمع المولة الثملية.

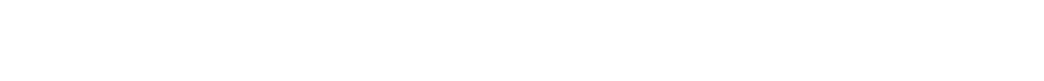

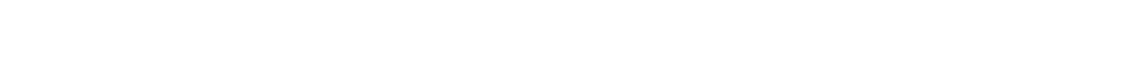

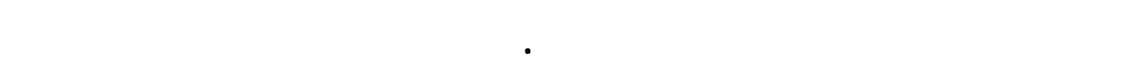

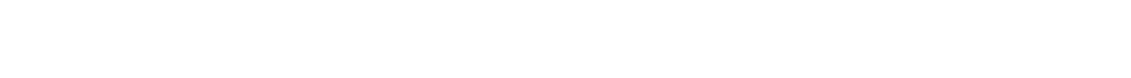

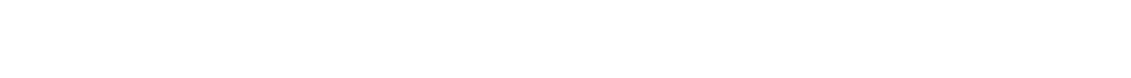

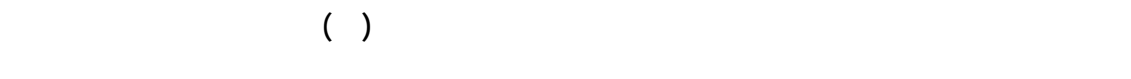
Rincon

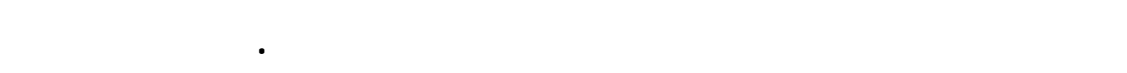

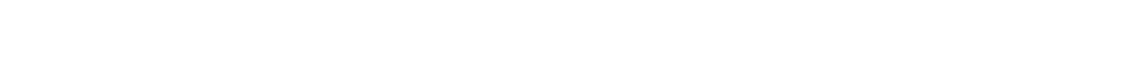

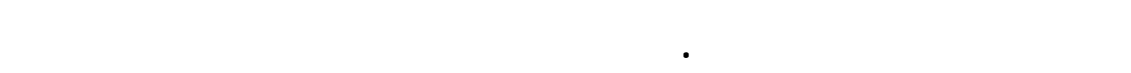

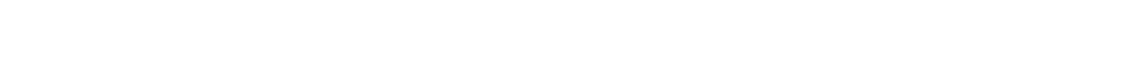

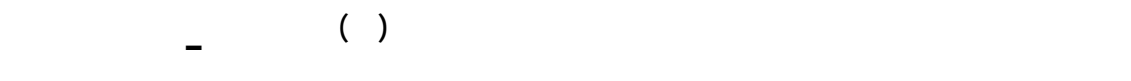

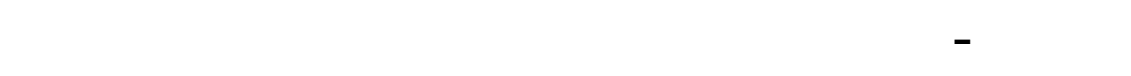

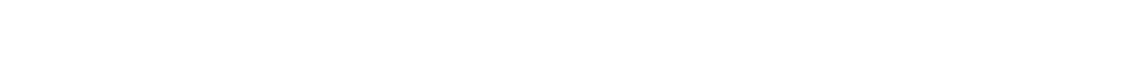

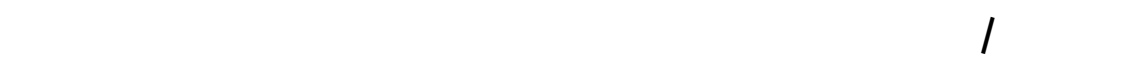

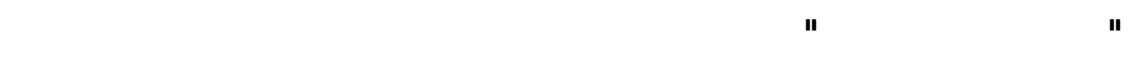

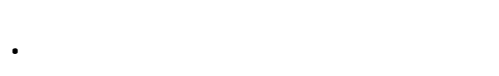

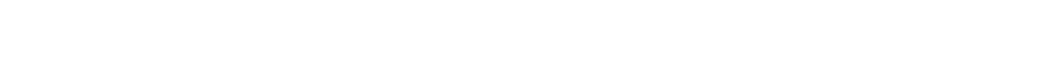

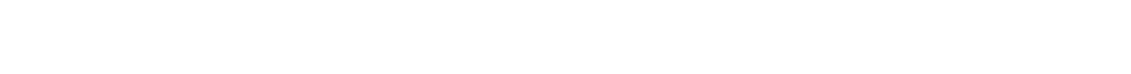

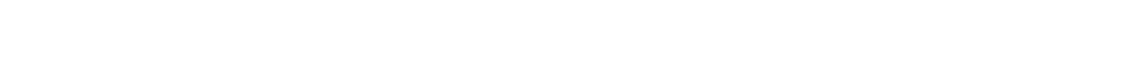




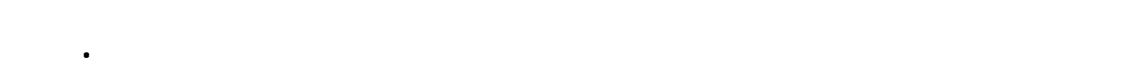

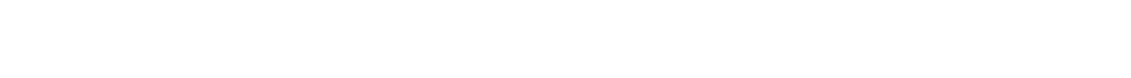

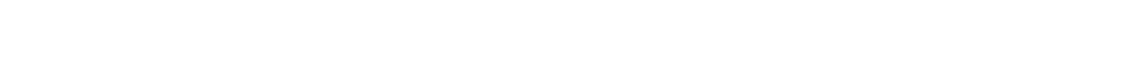

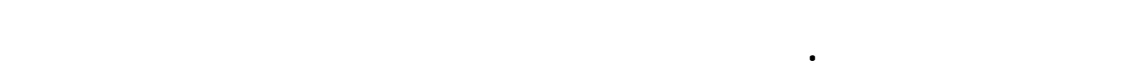

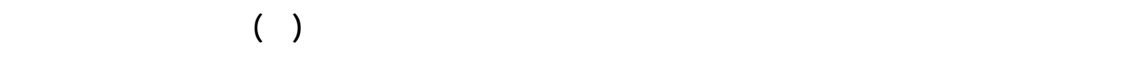

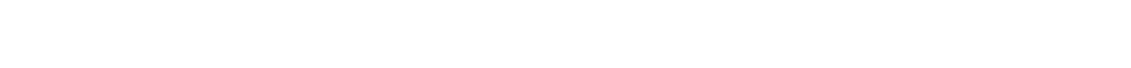

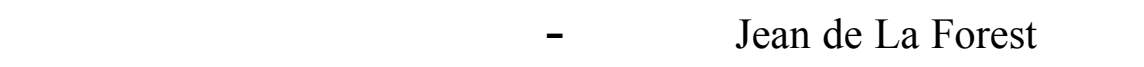

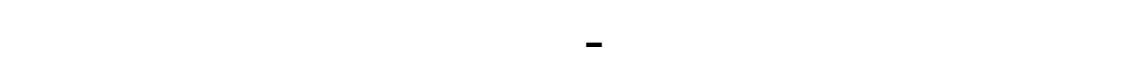

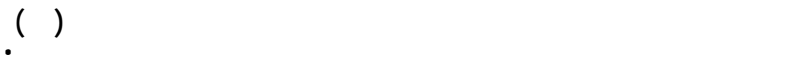

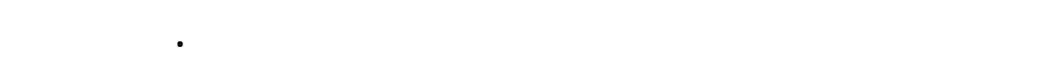

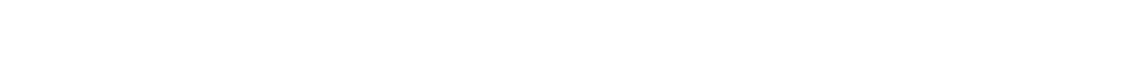

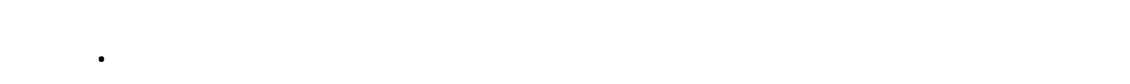

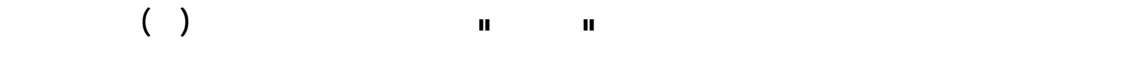

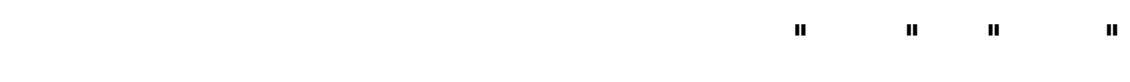

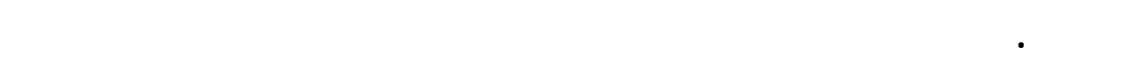

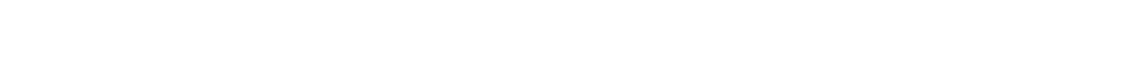

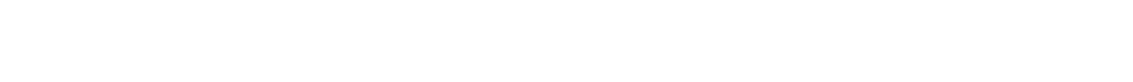

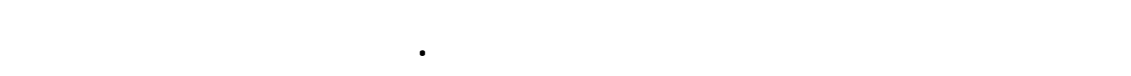

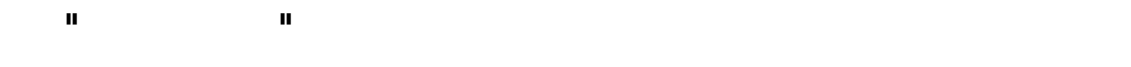

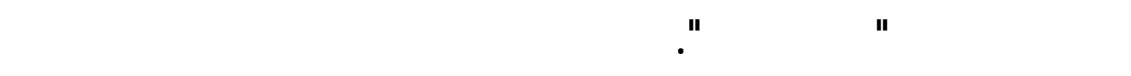

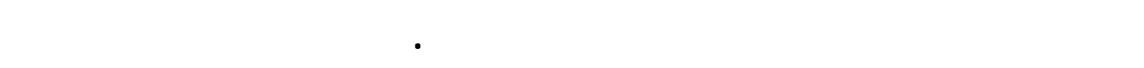

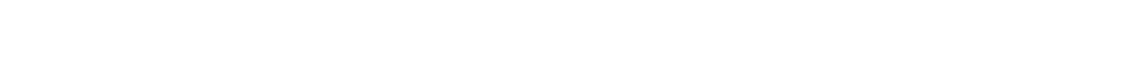




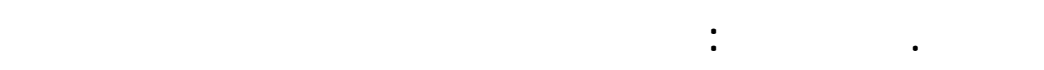

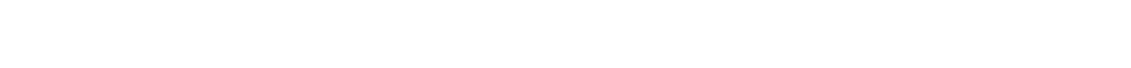

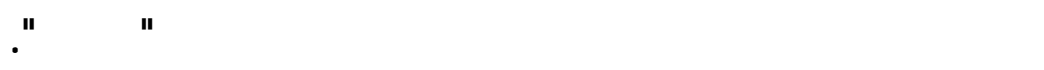

$$
\text { رابعًا- نسخة المرسوم المحفوظة في أوسير: }
$$

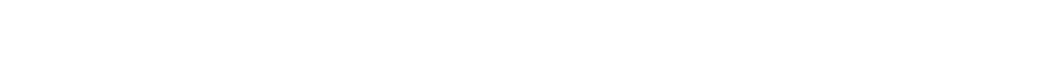

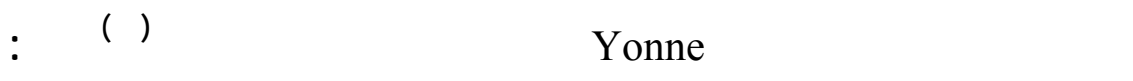

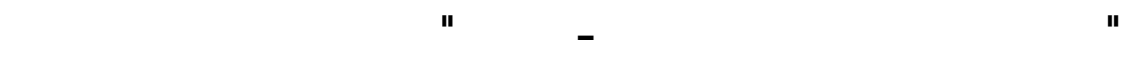

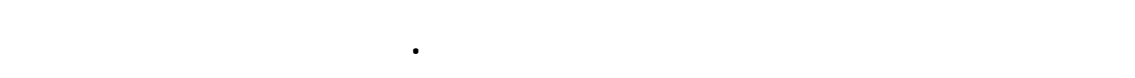

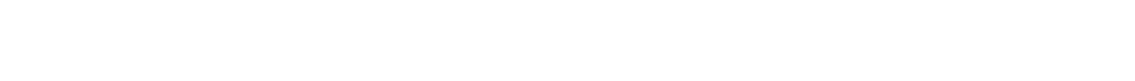

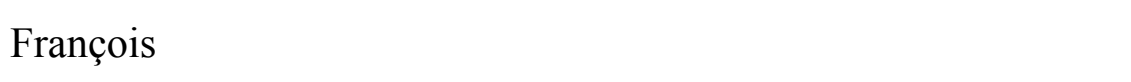
Savary Comte de Brèves

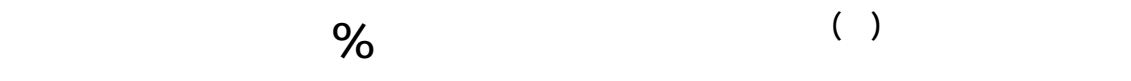

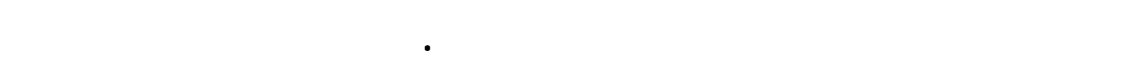

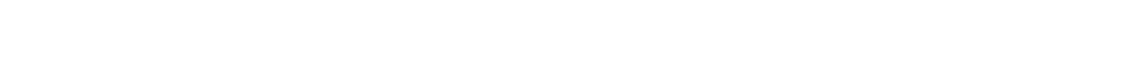

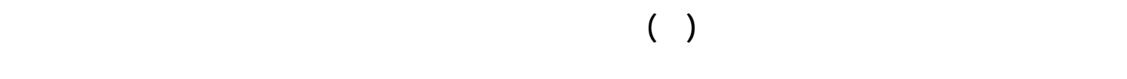

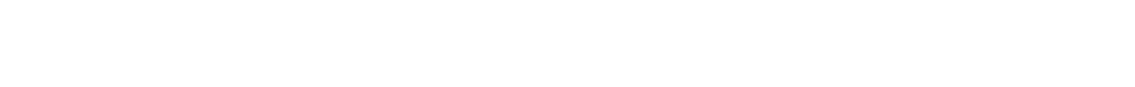

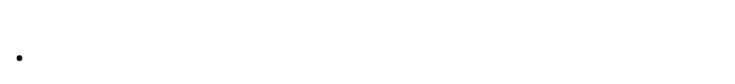

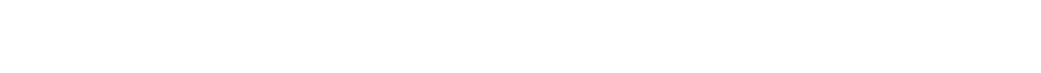

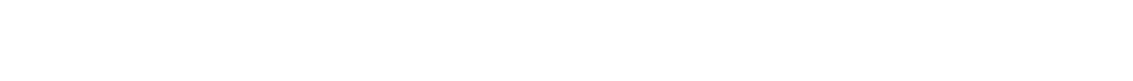

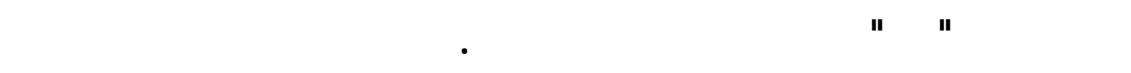

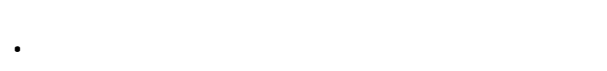

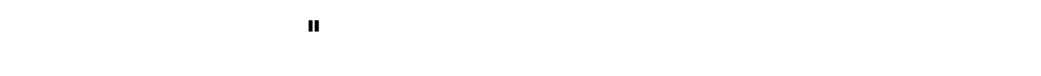

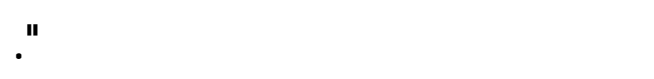


$\mathbf{v}$

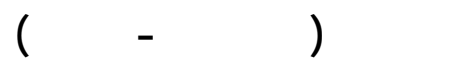

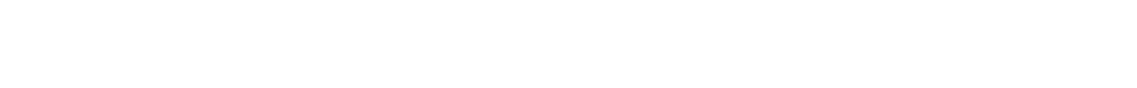

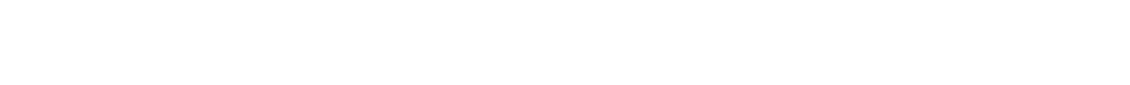

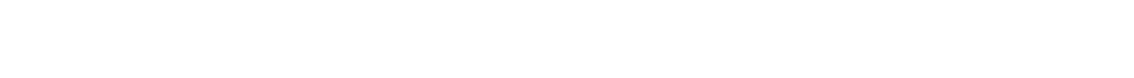

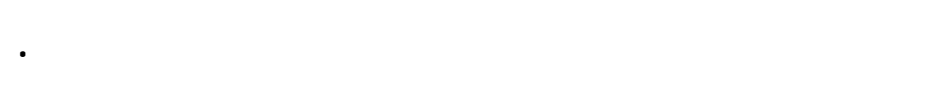




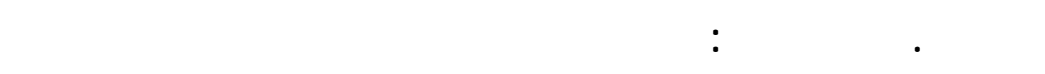

a

بسم المالرين الرحيم

السلالنسليملن المران

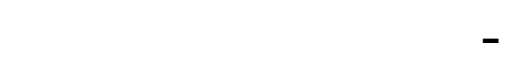

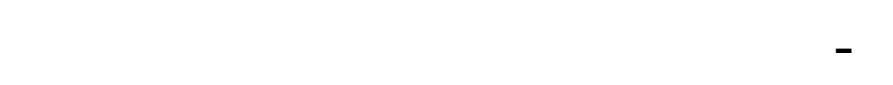

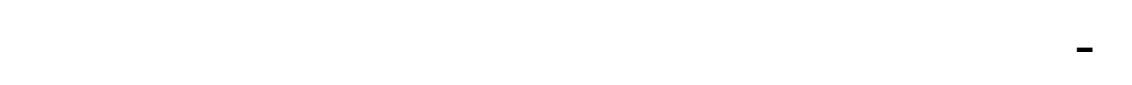

السكندي

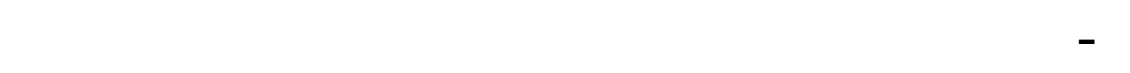

الكيلان وفلمرالسة

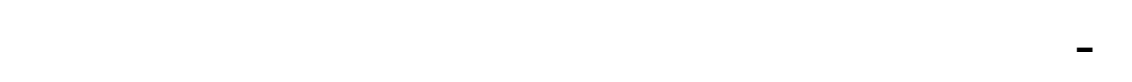

يشهد

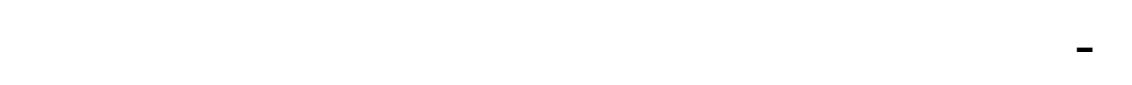

النوي والالان

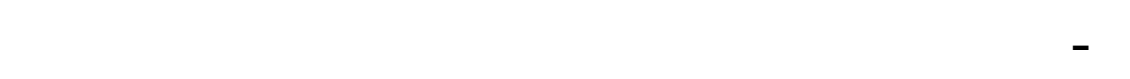

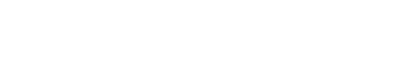

A 1

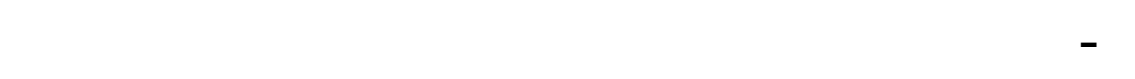

الكعص الولرين

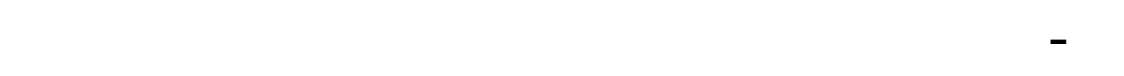

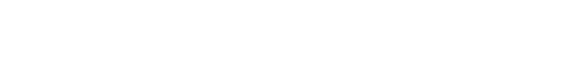

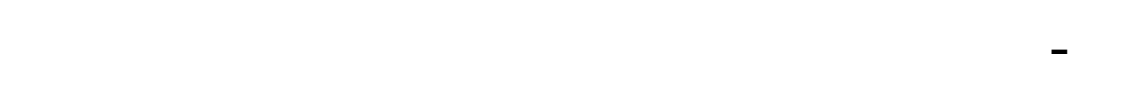

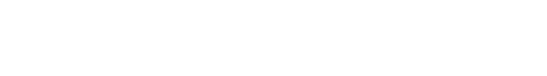


vq

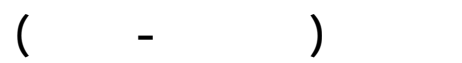

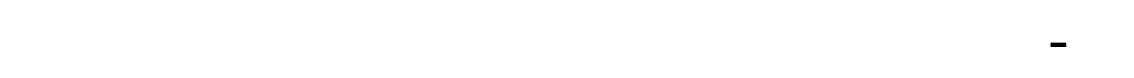

المولة الشرفة الفلهروضوضه

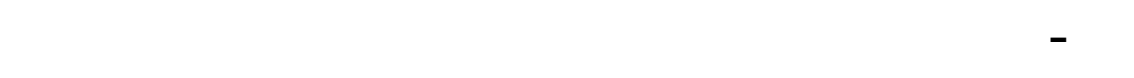

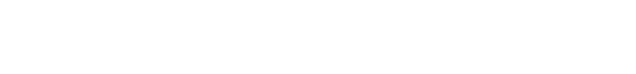

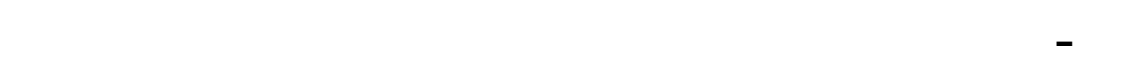

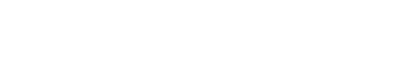

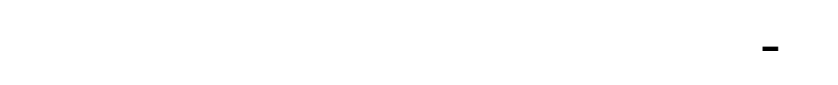

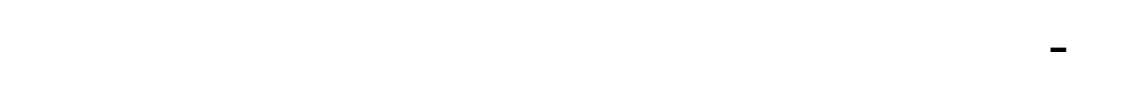

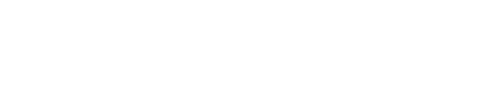

IV

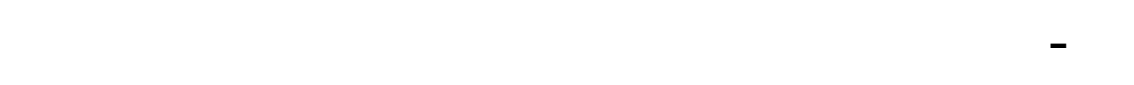

فليمكوامن ذالك الك

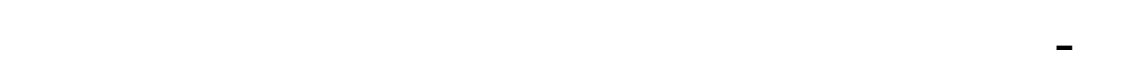

todid

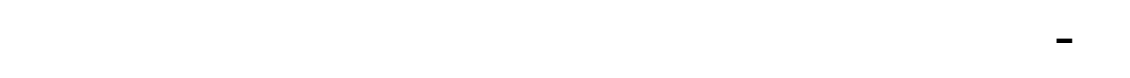

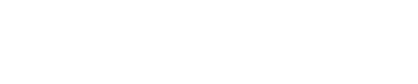

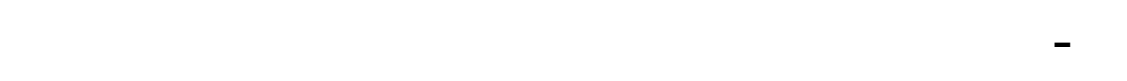

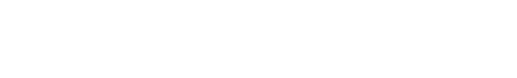

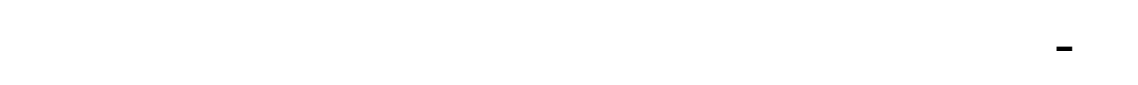

الهرائة بالغرب

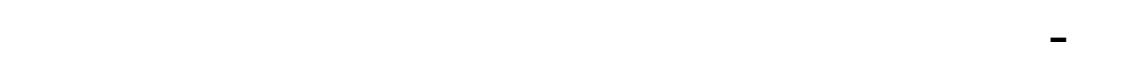

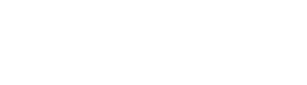




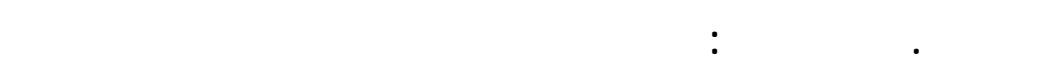

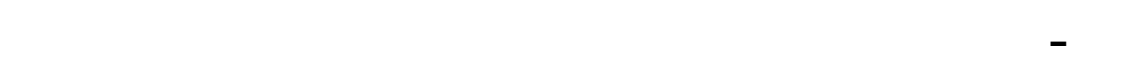
لوعن فل

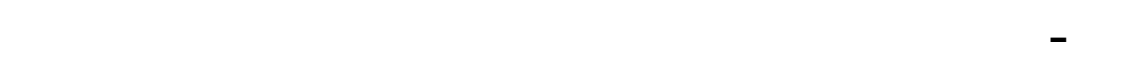

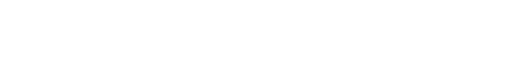

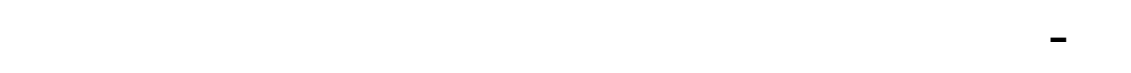
ذالك ويسام لفمل الكنيلان والهرالنة

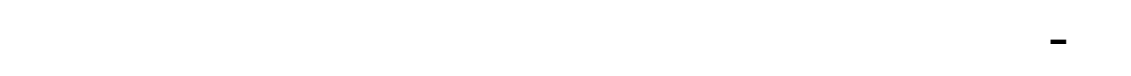

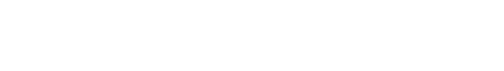

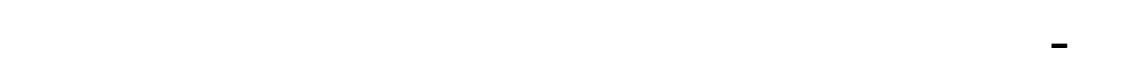

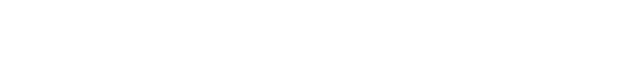

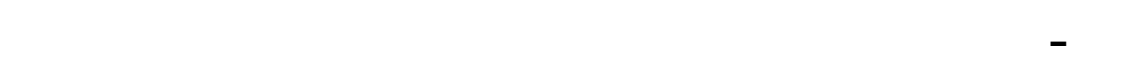
شيئامن البنالع

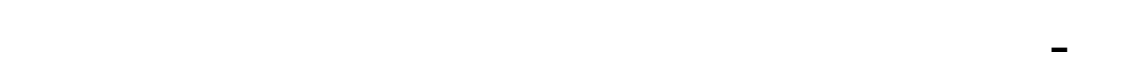

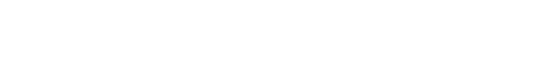

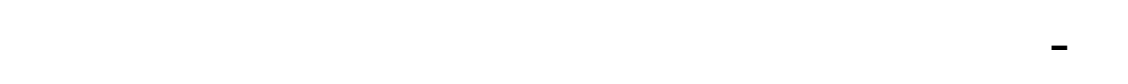

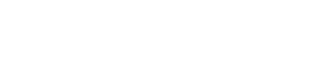

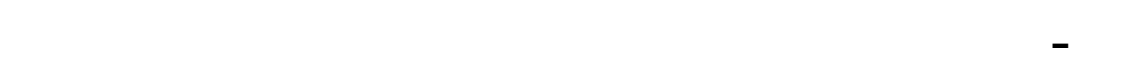
لاكمة هضر الفهل خلا المموالهرلح

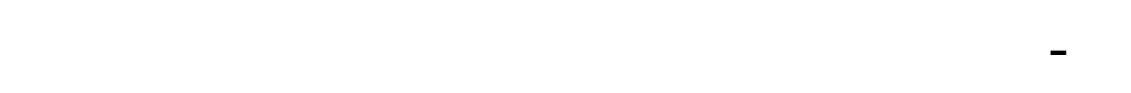
القومةقلسفره

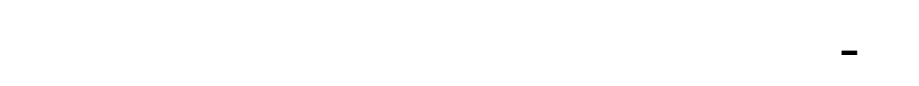

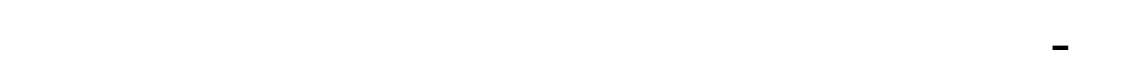
باجةفاليكتفها 
A)

الروزلة (لكد السانتر-r| -rr)

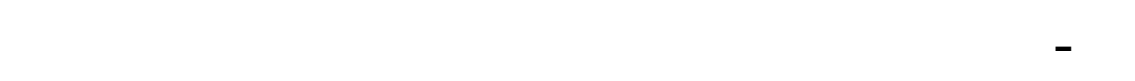

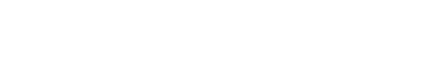

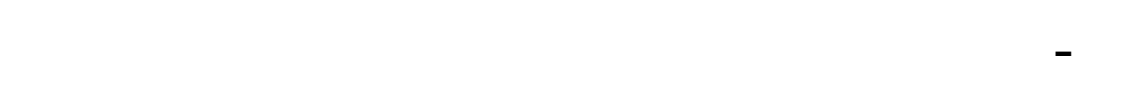
جالب عل

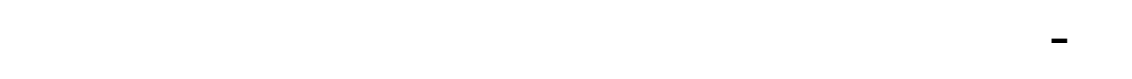

فهه خلمة فهل

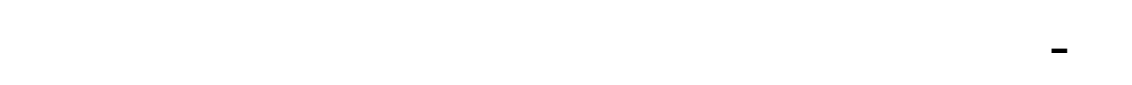

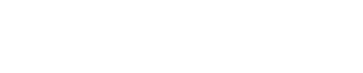

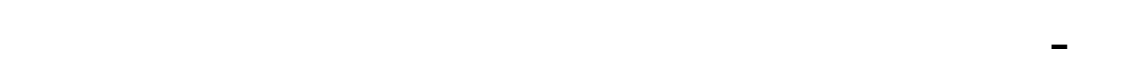

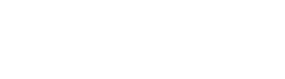

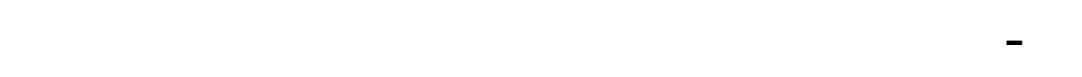

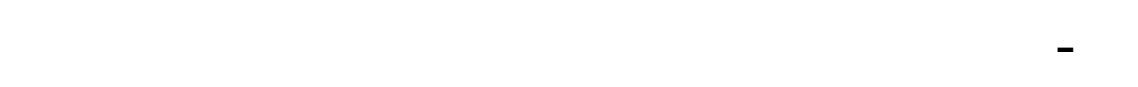

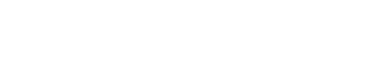

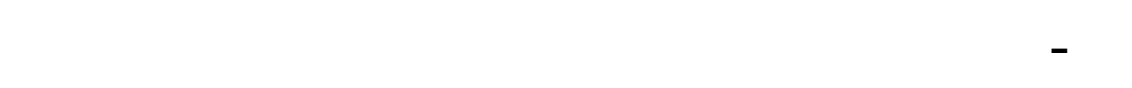

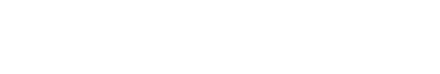

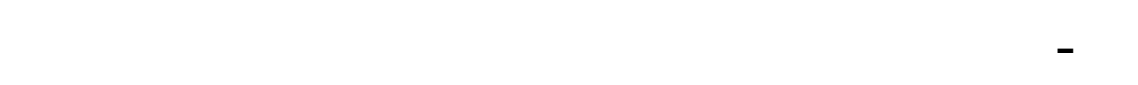

لهرالنة

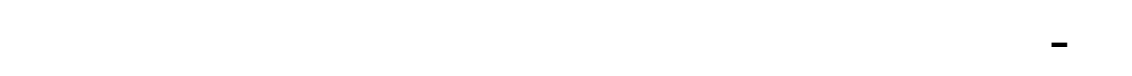

ياتو أحدمن لالر الكنيلان

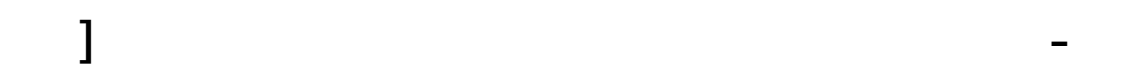

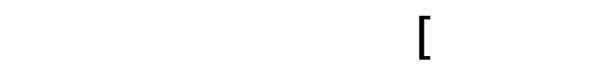

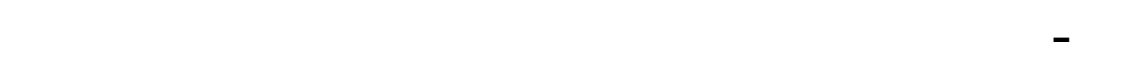

أبناجنه 


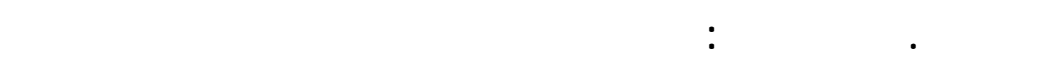

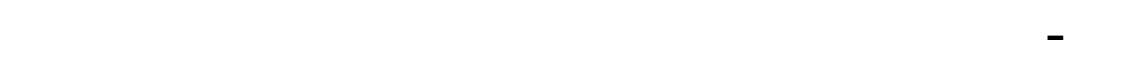
علماقيقضيه الثرة

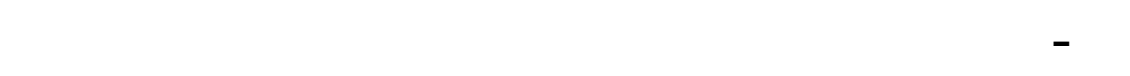

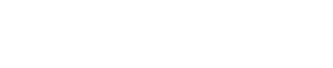

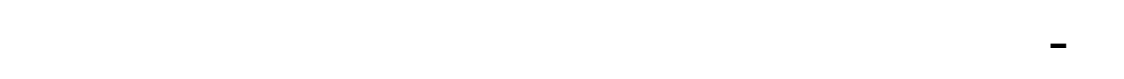
كن الديول الثرف

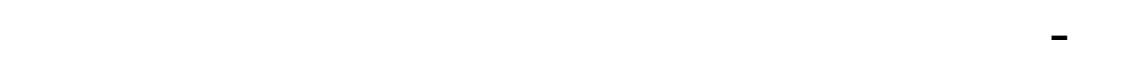

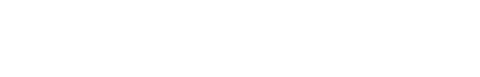

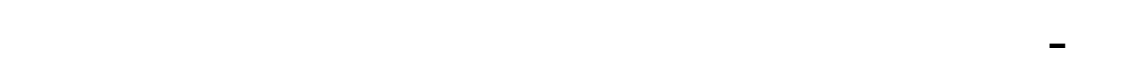
منها المنالق

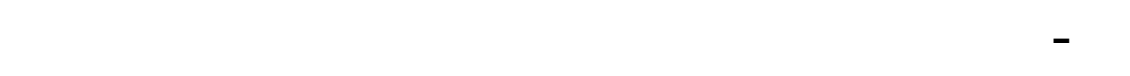

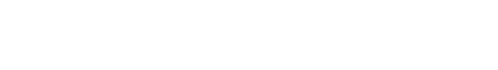

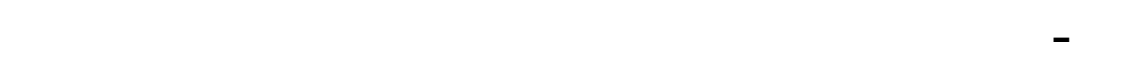
الأمناءعل اللمالة

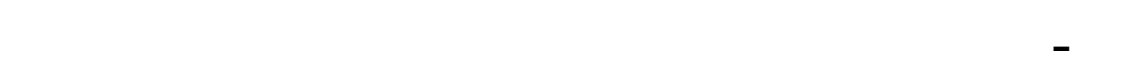
تلثتش

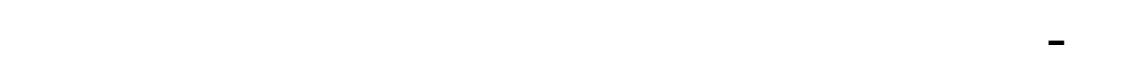

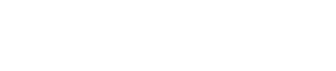

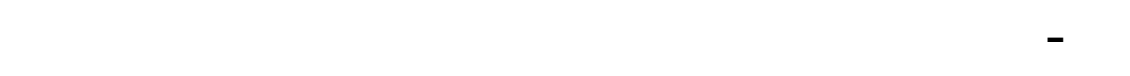
إذكمرن ولا يأخنوا

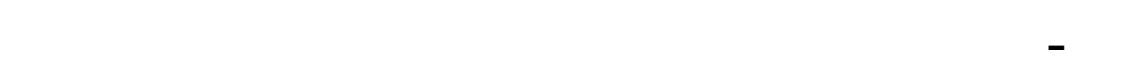

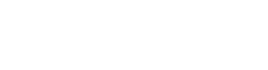


$\boldsymbol{\Lambda} \boldsymbol{r}$

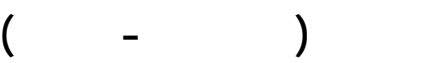

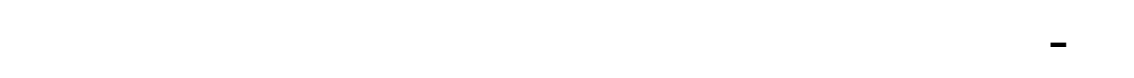

جلمكية

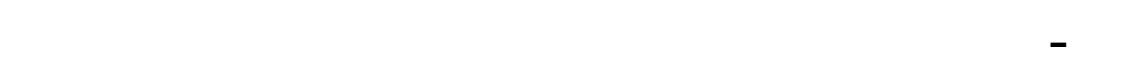

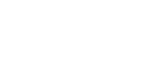

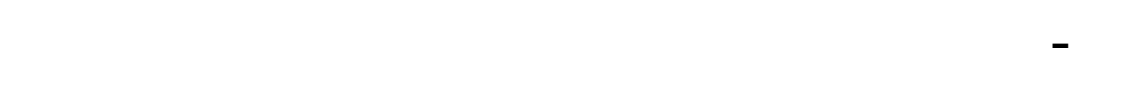

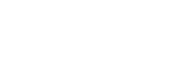

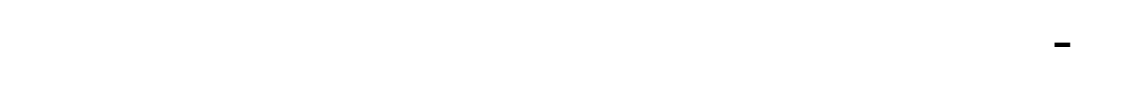

وجمط البعفلا يمق

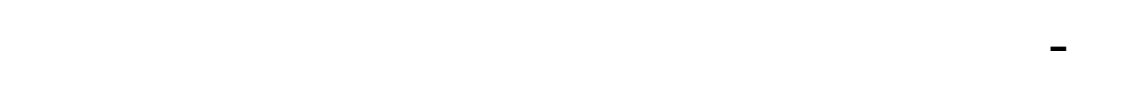

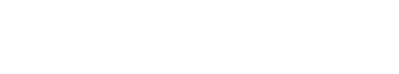

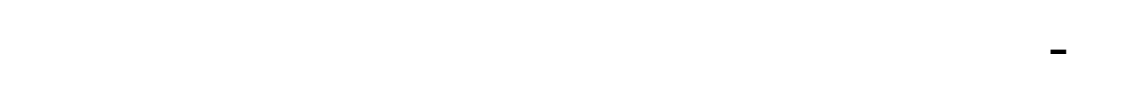

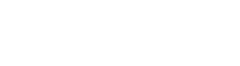

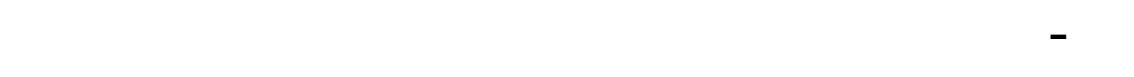

مأكلى

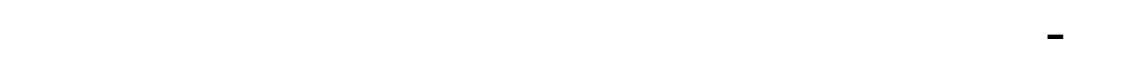

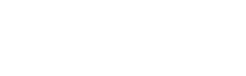

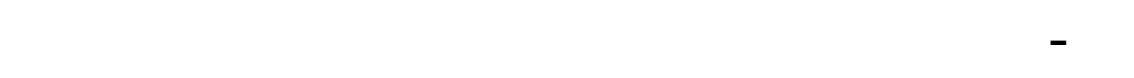

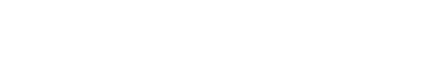

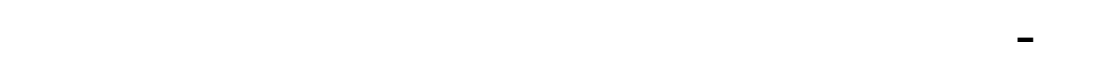

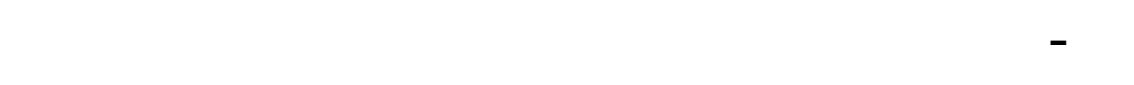

لd

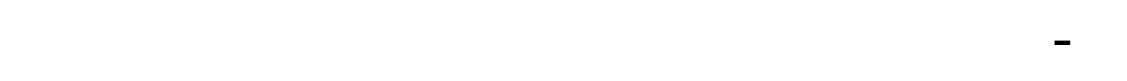

والهولا الأخهن أخه 


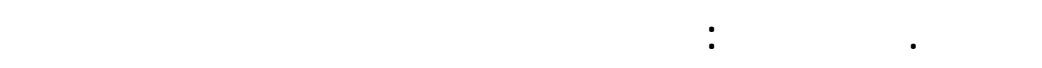

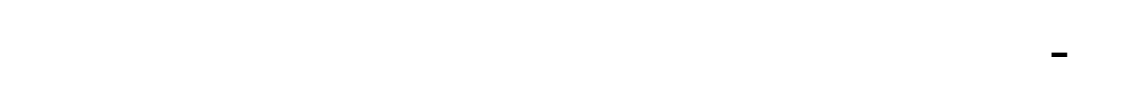
ضidiاولا كيلا

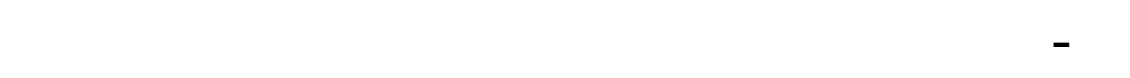
حيثل

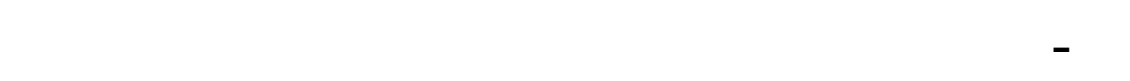
يؤخذمهم ذخطة

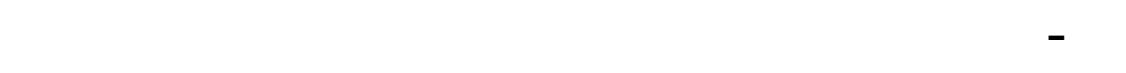
الخا

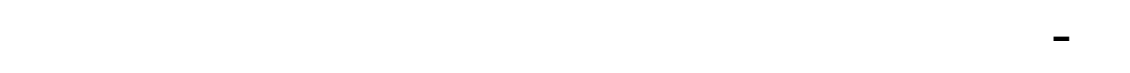

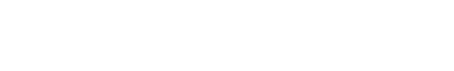

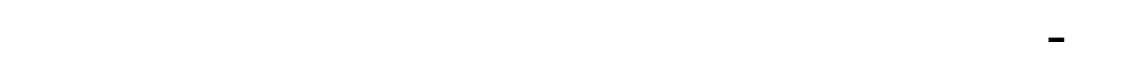

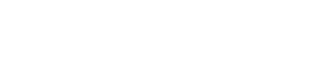

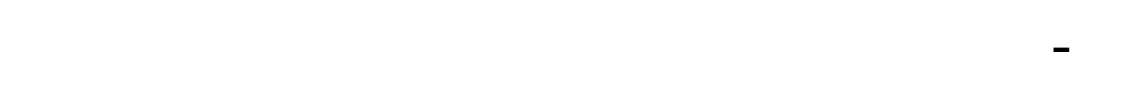

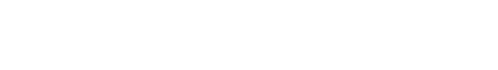

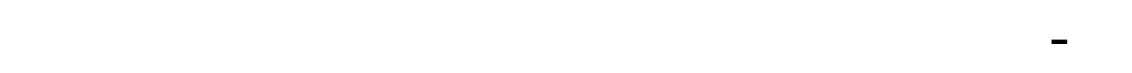
السكندري الهعص عل الفصليشهرالبشهر

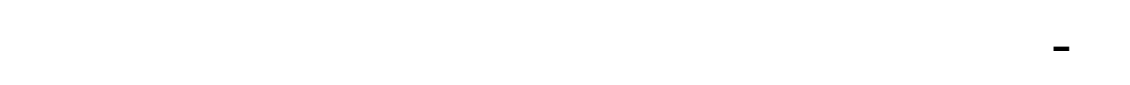

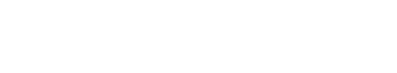

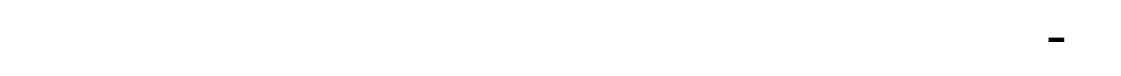

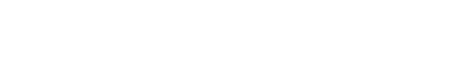

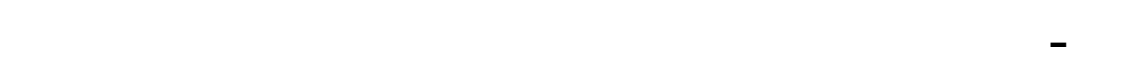

التلاجر 
10

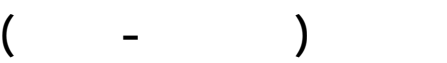

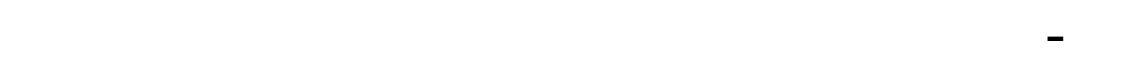
معن التالمون الفبلية

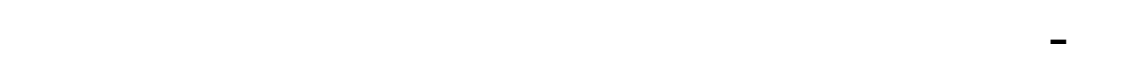

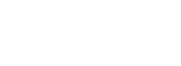

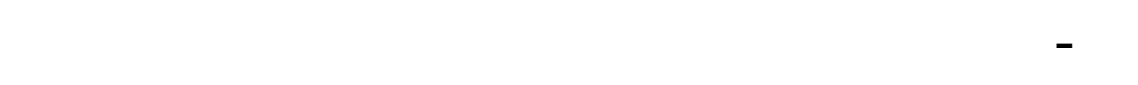

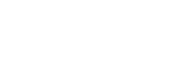

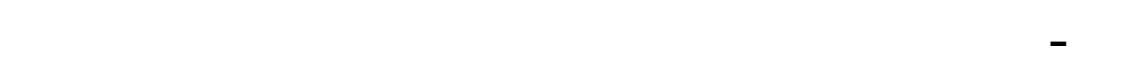

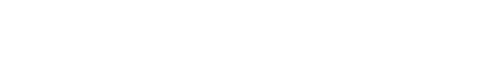

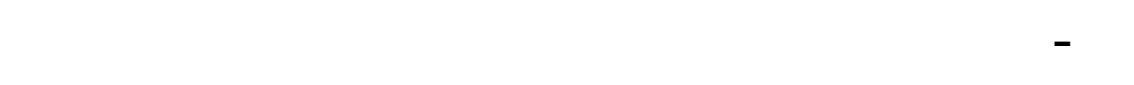

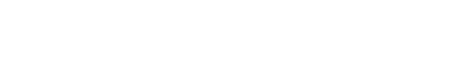

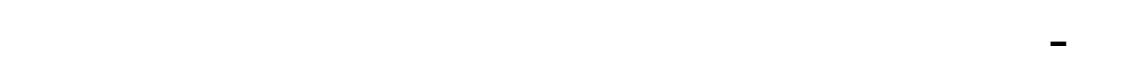

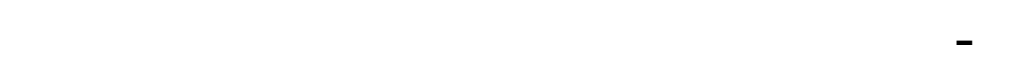

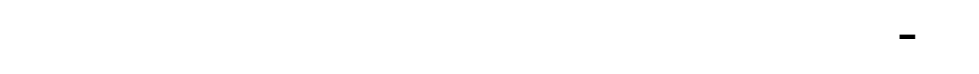

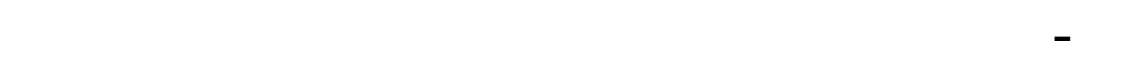

الثرط

19 - لهمبرحوالوصية التلفجلوله لهرنج الكنيلان ولهرانمة

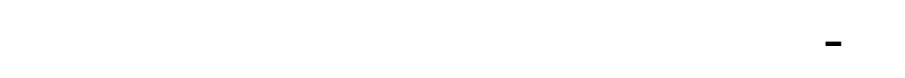

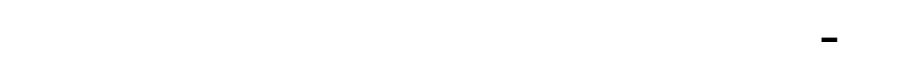

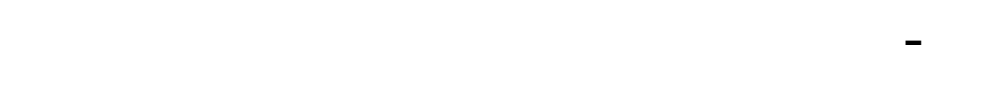

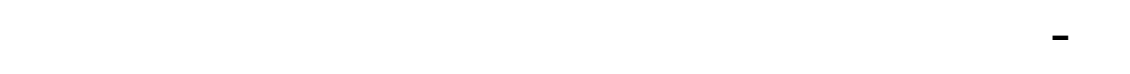

كرولا

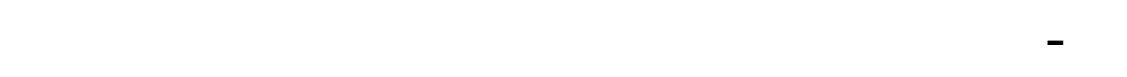




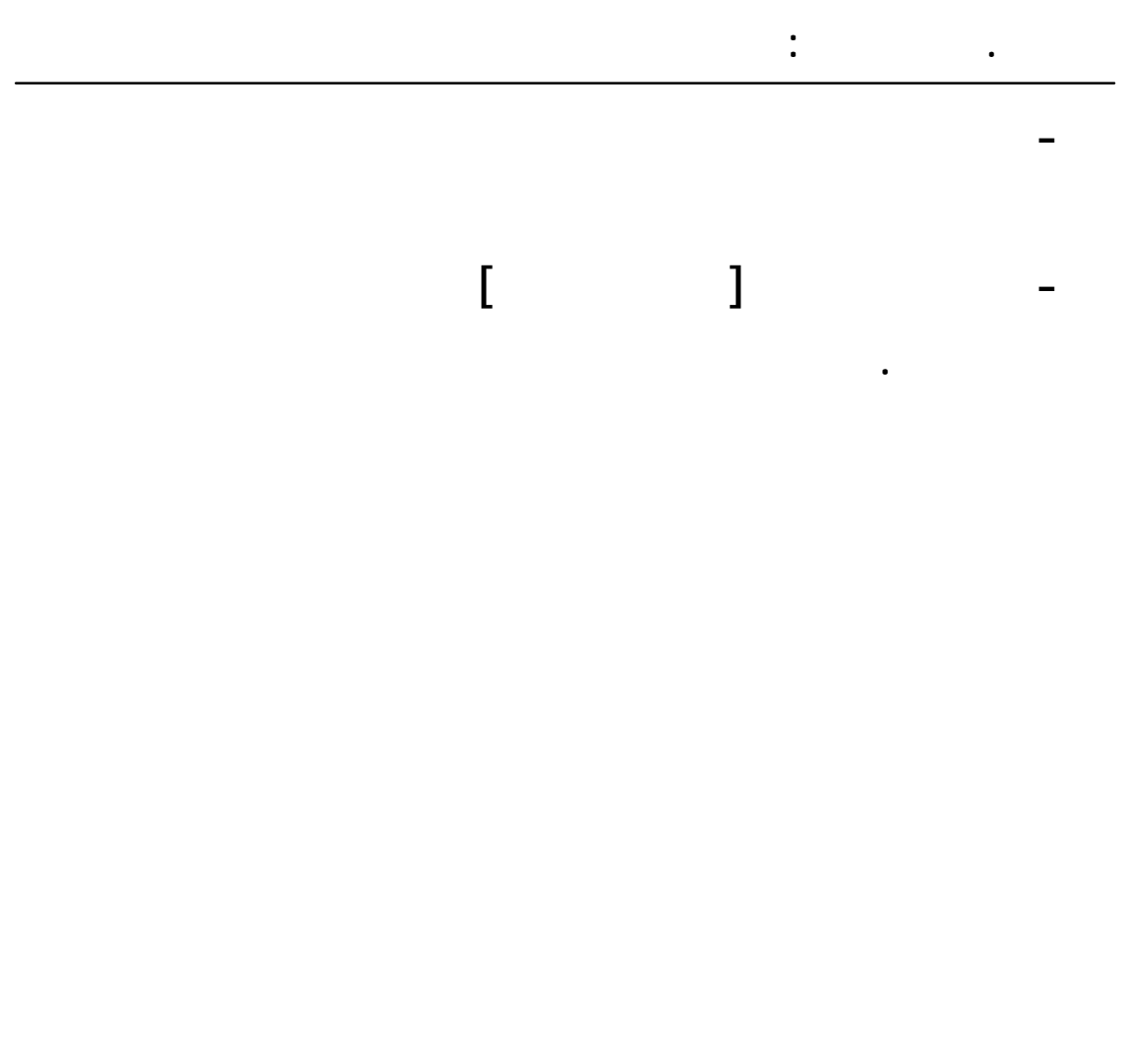




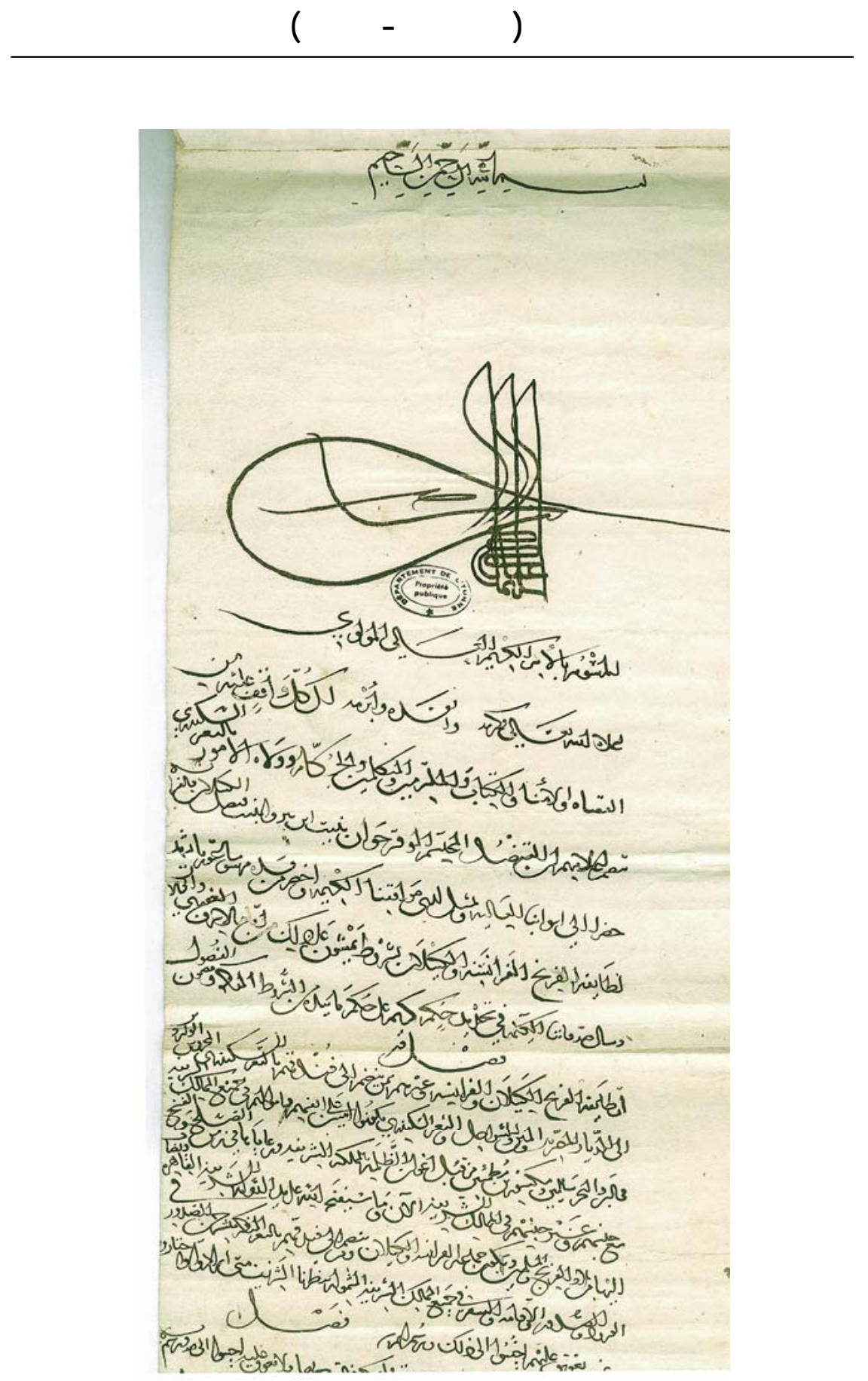




\section{د. M M}

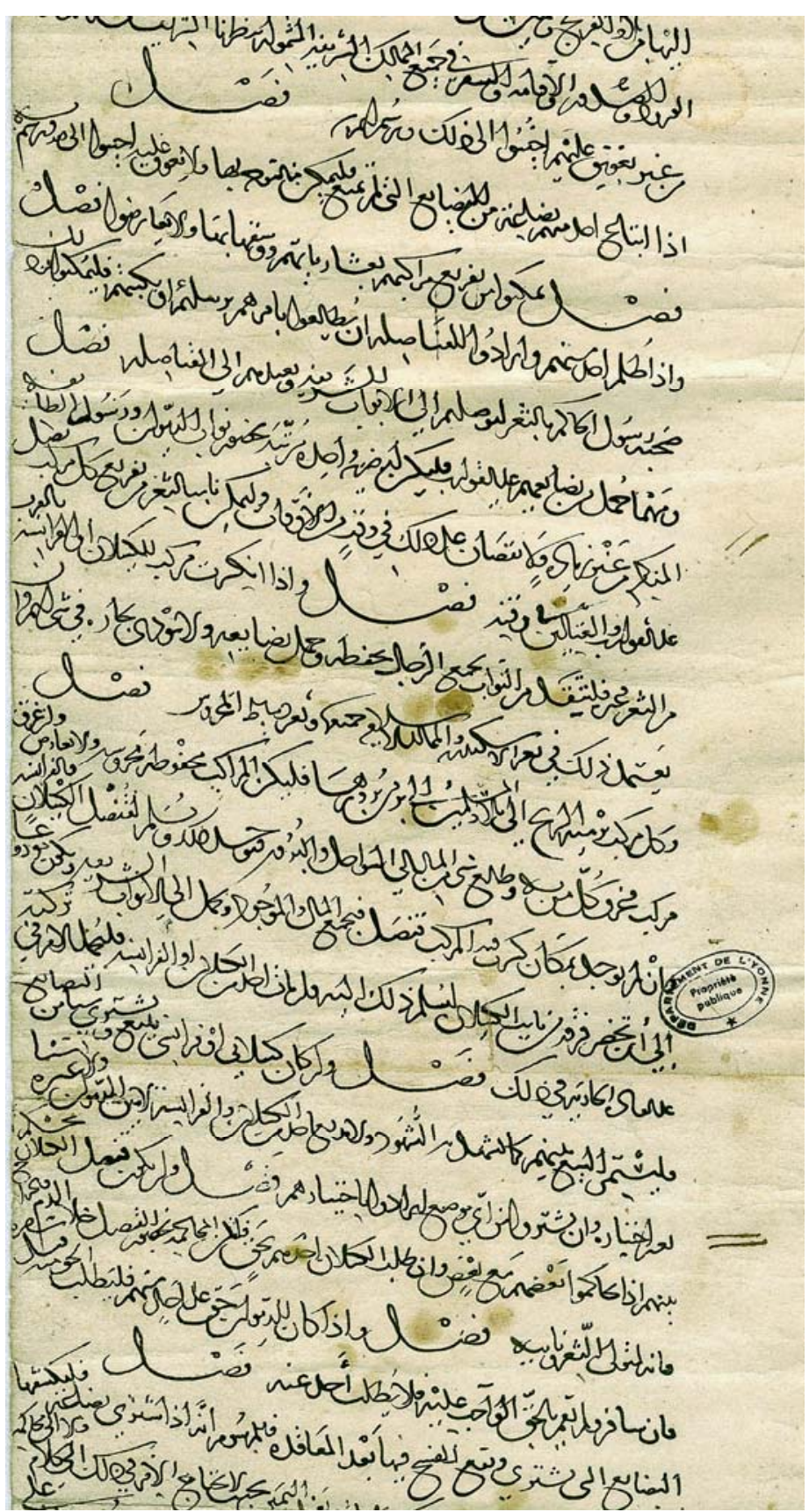




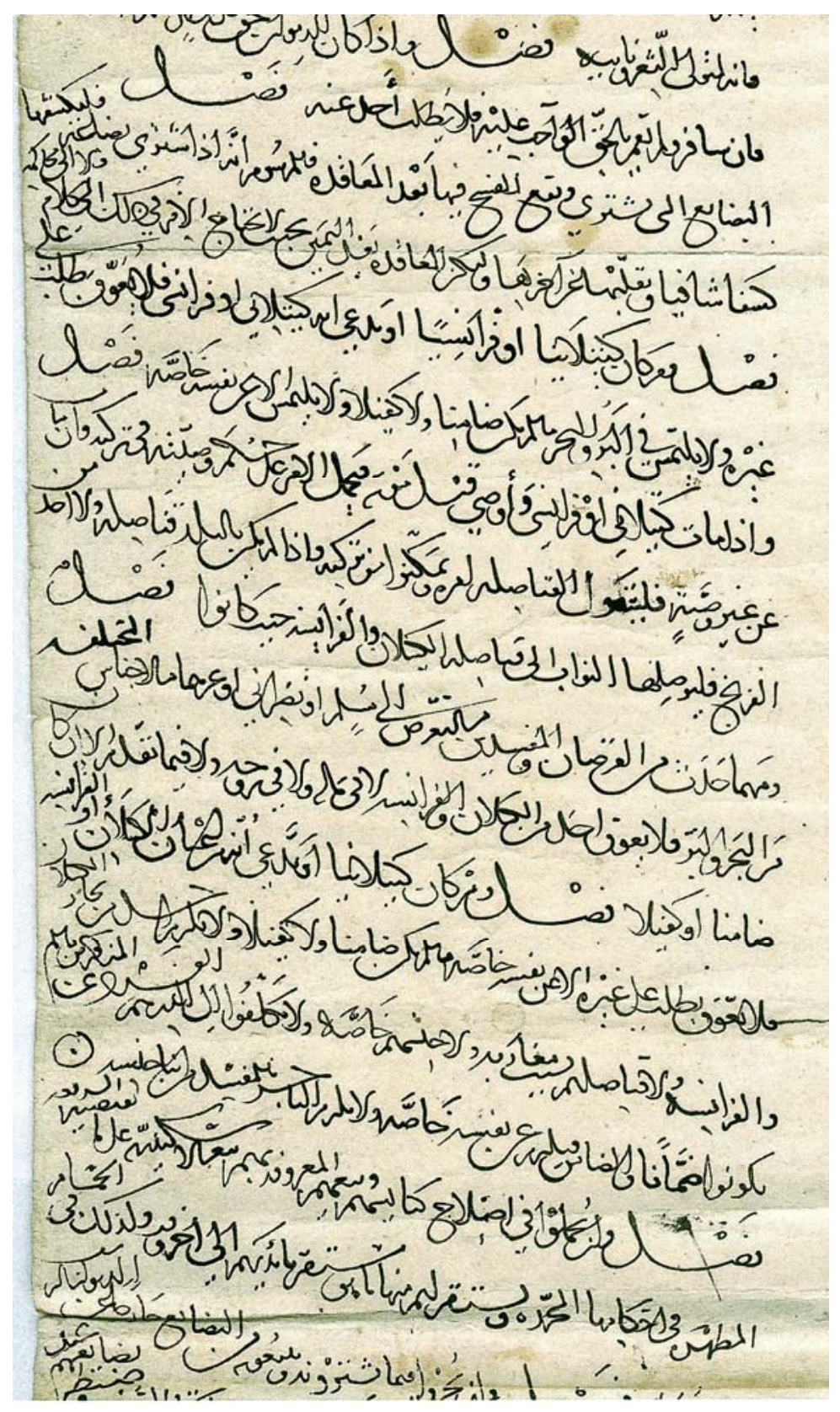




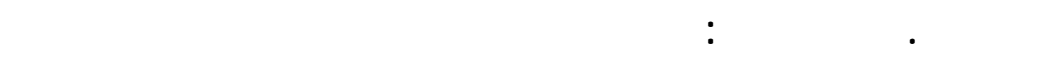

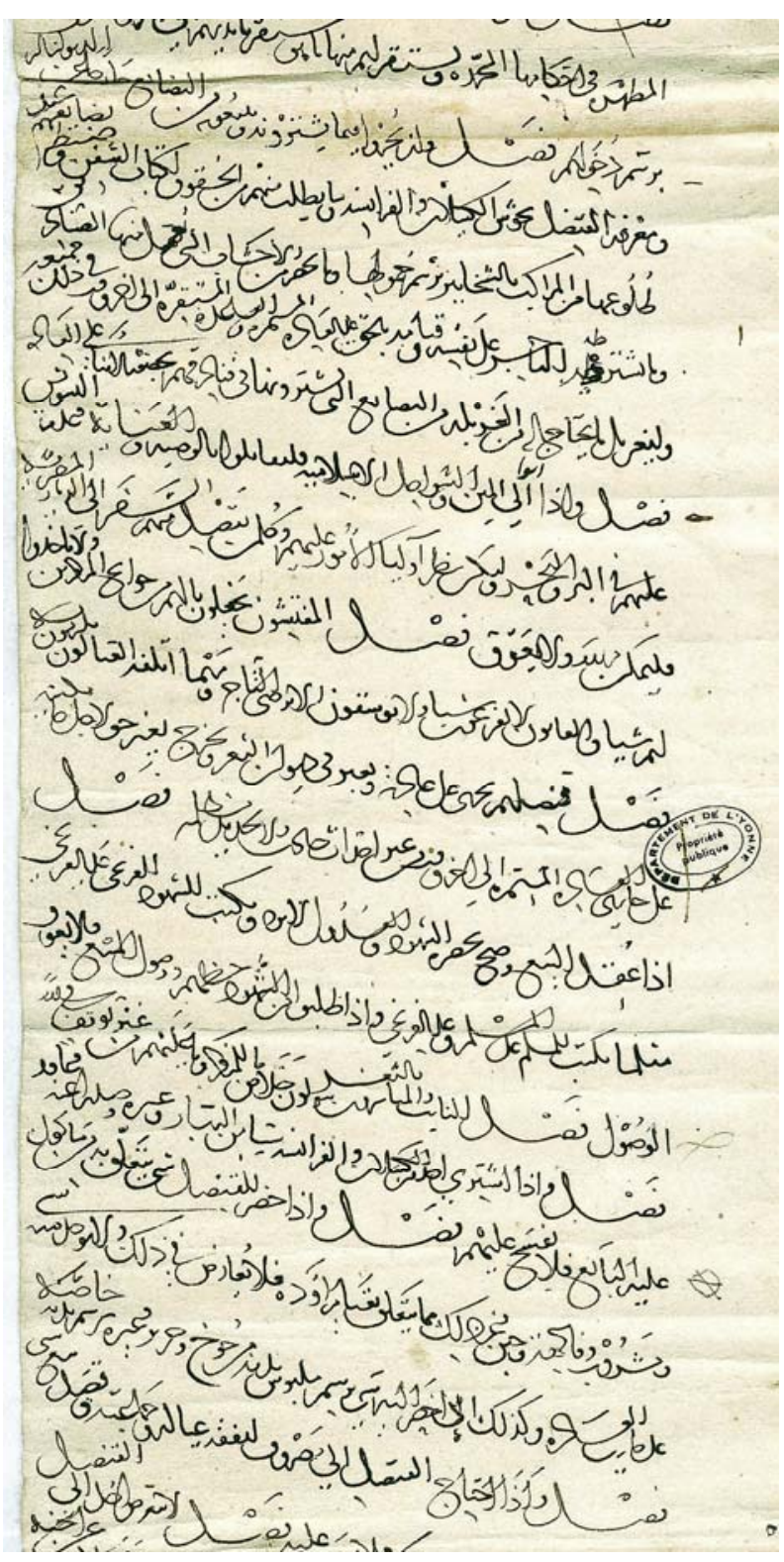




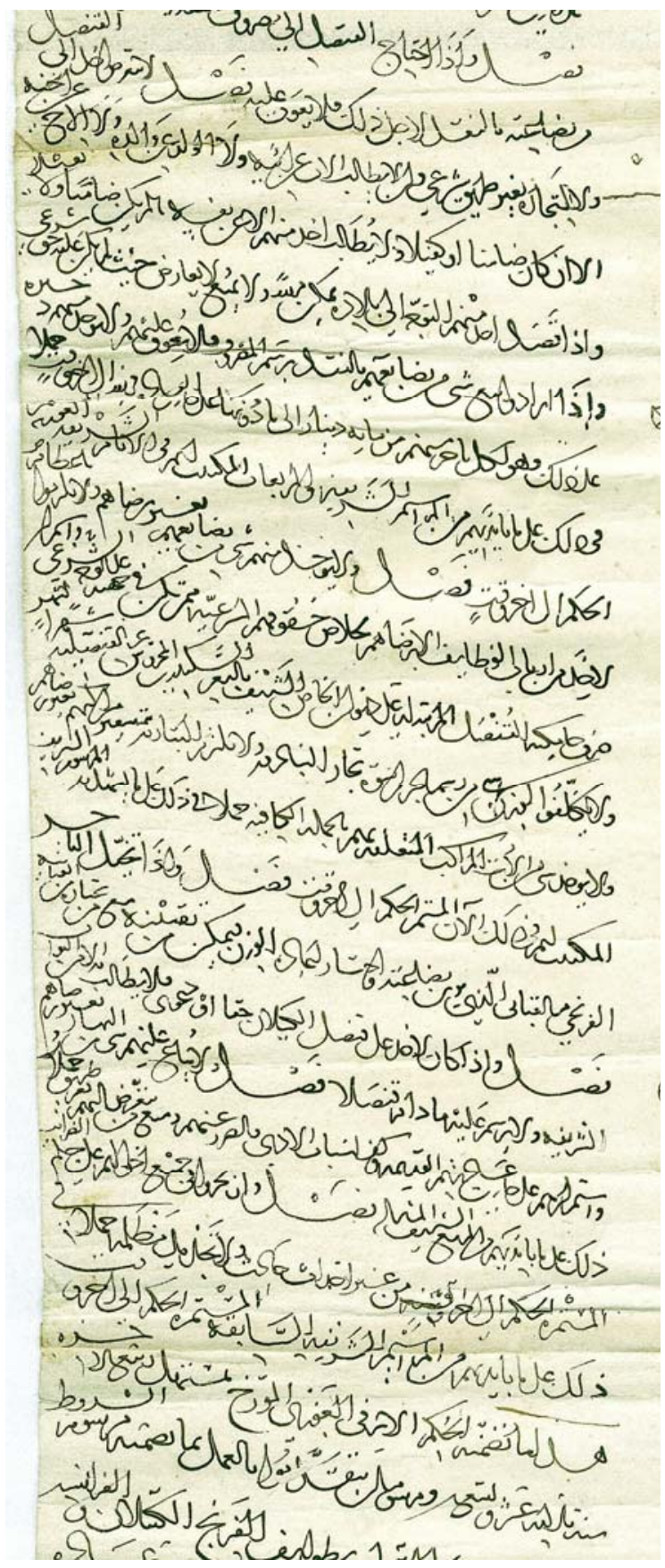




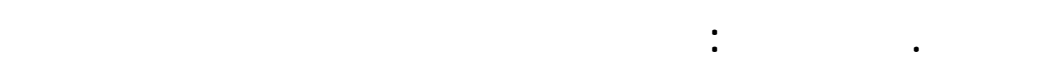

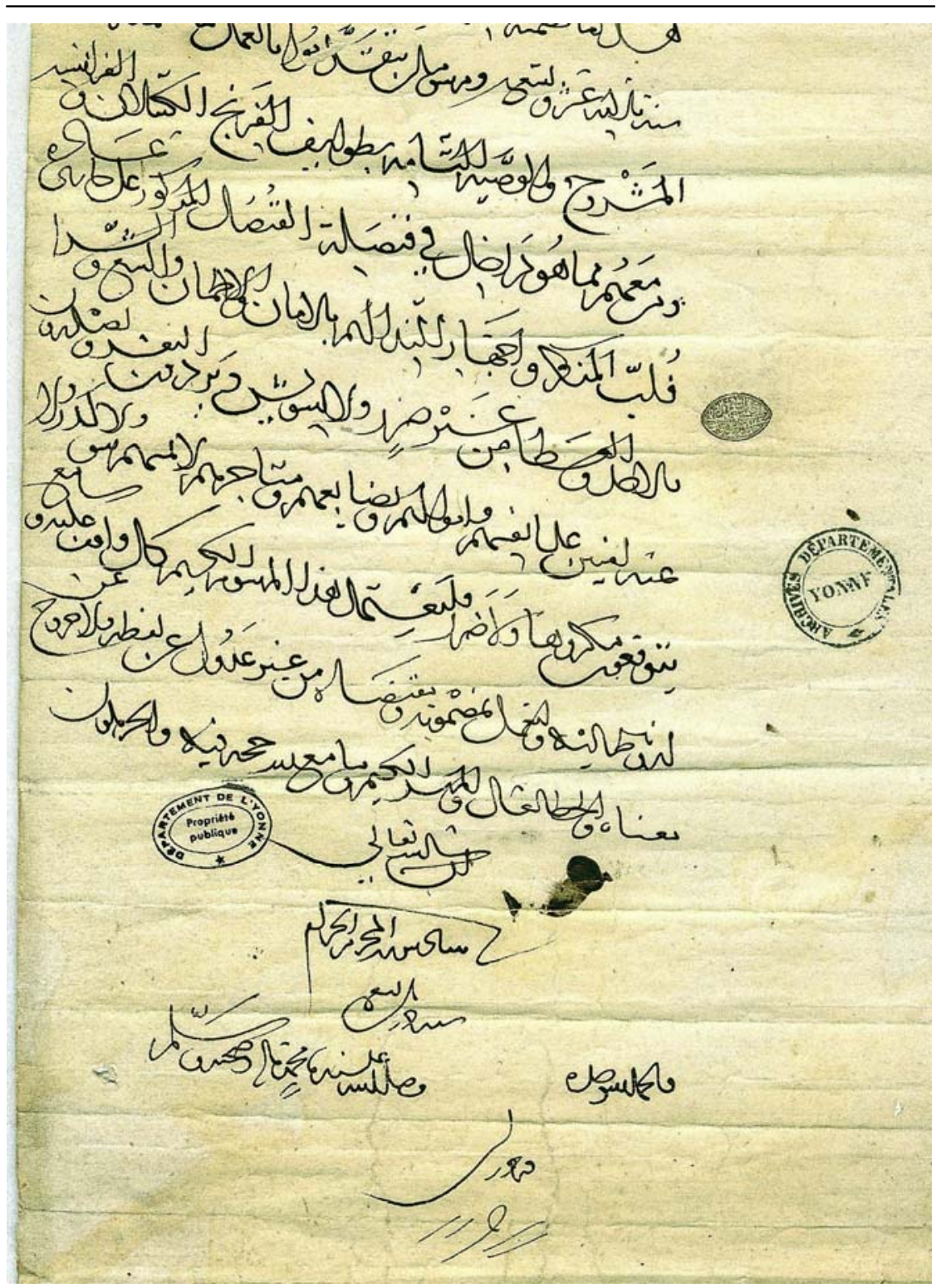




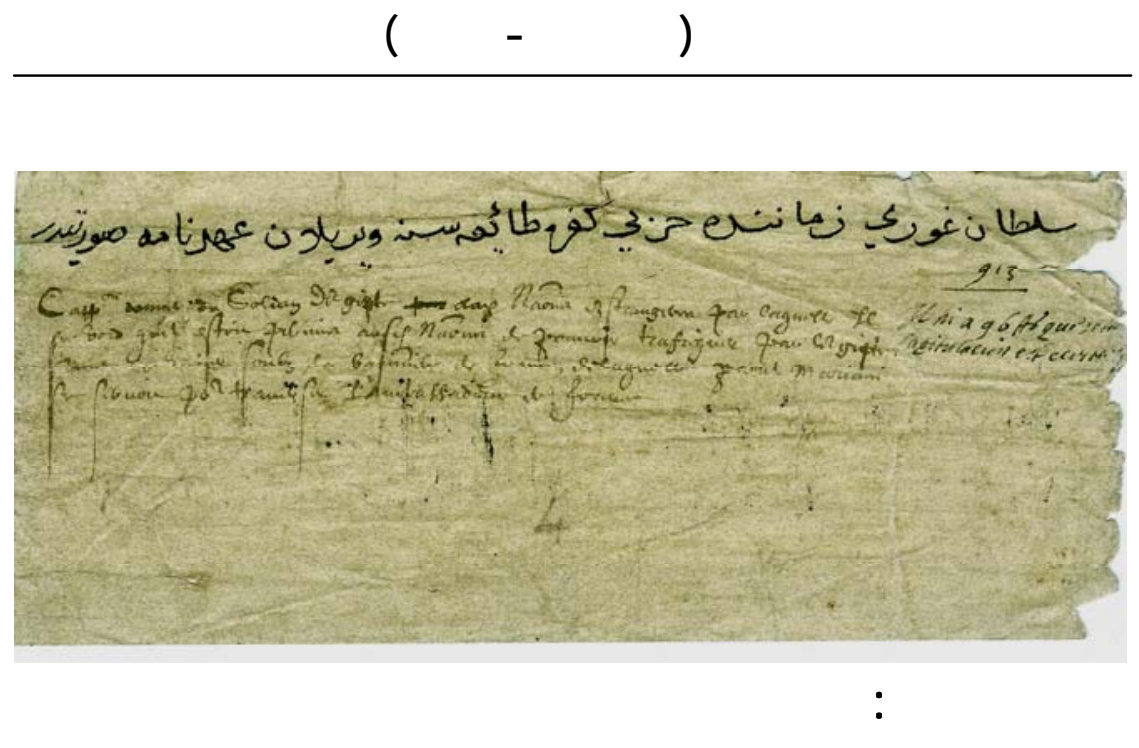

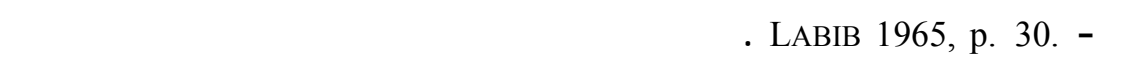
ولكرابع بآخرالجم.

HEERS 1997, p. 91-92 et 246. -

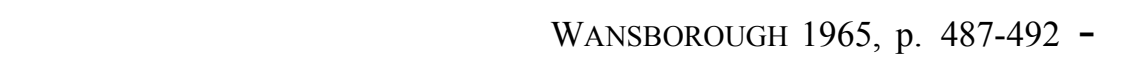

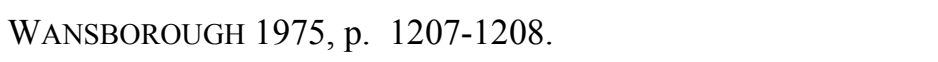

$$
\begin{array}{r}
\text { Mollat 1988, p. 170-1. - } \boldsymbol{\varepsilon} \\
\text { HeERs 1997, p. 240. - } 0
\end{array}
$$

MARTIN-CORRALES 2000, p. 223 ; WANSBOROUGH 1963, p. 504-5. - 7

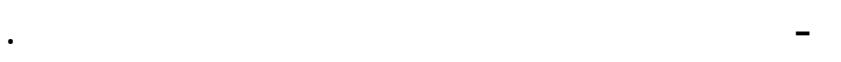

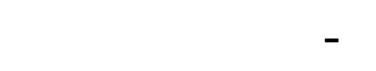
CHARRIÈRE 1848-1860, p. 122-129 - 9

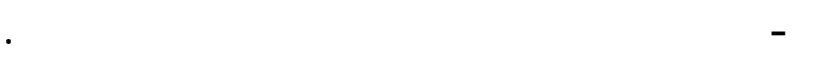
SALLES 1896, p. 16-18 - II P. BRUMMET 1994, p. 22-26. - ו וז

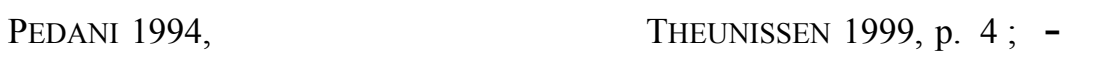
p. $59-60$ 


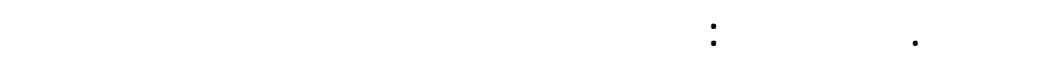

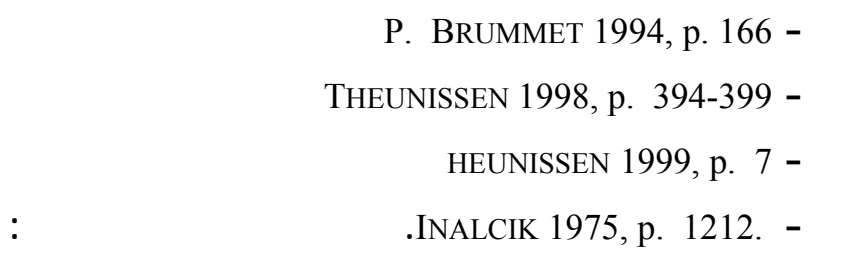

MORITZ 1915,p. 422-443 ; THEUNISSEN 1999, p. 6-7.

THEUNISSEN 1999, p. 2-29; THEUNISSEN 1998, p. 400-414. - I

URSU 1908, p. 7-8. - 19

VATIN 1994, p. 325-326 - r.

URSU 1908, p.30-35 ; CHARRIERE 1848-1860, I, p. 116-119 - rI

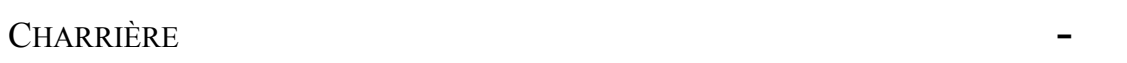

1848-1860, t. 1, p. 119

URSU 1908, p. 41-53 ; CHARRIERE 1848-1860, t. 1, p. 121-132 - שי

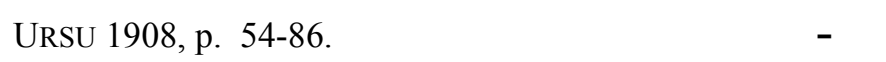

INALCIK 1975, p. 1213 ; MATUZ 1992, p. 183-190 ; URSU 1908, - ro p. $87-97$;

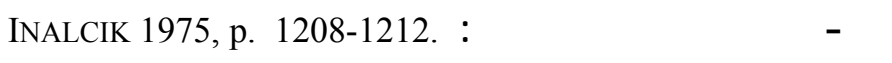

Archives départementales de l'Yonne série F, n 240 - rV

BACQUE-GRAMMONT et alii 1991, p. 16 - ג

Jacques de CASTEL, Relation des voyages de M. de Brèves, tant en - $\mathbf{q}$

Grèce, Terre-sainte et d'Égypte, qu'aux royaumes de Tunis et d'Alger,

Paris, 1628 
- BAquÉ-GrAmMOnT et alii 1991 = J.-L. BACQUÉ-GRAMMONT, F. Hitzel, S. KunelRALP, Représentants permanents de la France en Turquie (1536-1991) et de la Turquie en France (1797-1991), Istanbul, Isis, 1991.

- Brummet 1994 = P. Brummet, Ottoman Seapower and Levantine Diplomacy in the Age of Discovery. New York, SUNY, 1994.

- Castel 1628 = J. Castel, Relation des voyages de M. de Brèves, tant en Grèce, Terre-sainte et d'Égypte, qu'aux royaumes de Tunis et d'Alger, Paris, 1628.

- Charrière 1848-1860 = E. CharriÈre, Négociations de la France dans le Levant ou correspondances, mémoires et actes diplomatiques des ambassadeurs de France à Constantinople, Paris, 4 vols., 1848-1860.

- HeErs 1997 = J. HeERs, Jacques Coeur, Paris, Perrin, 1997.

- INALCIK $1975=$ H. INALCIK, art " Imtiyāzāt». Empire ottoman, Encyclopédie de l'Islam, vol. III, 1975, p. 1208-1219.

- LABIB 1965 = S. LABIB, Handelsgeschichte Ägyptens im Spätmittelalter 1171-1517, Wiesbaden, Franz Steiner, 1965.

- Martin-Corrales $2000=$ E. Martin-Corrales, Comercio de Cataluna con el Mediterraneo. El comercio con « los enemigos de la fe », Barcelona, Bellateria, 2000.

- $\quad$ MAtuz 1992 = J. MAtuZ, « A propos de la validité de la capitulation de 1536 entre l'Empire ottoman et la France », Turcica 24, 1992, p. 183-190.

- Moritz 1915 : B. Moritz, «Ein Firman des Sultan Selim für die Venetianer », dans Festschrift Sachau zum siebzigsten Geburtstag, Berlin, Reimer, 1915, p. 422-443.

- SAlles $1896=$ G. SAlles, Les origines des premiers consulats de la nation française à l'étranger. D'après des documents inédits extraits principalement de la Bibliothèque impériale de Vienne, des Archives des Bouches-du-Rhône et de la Bibliothèque nationale de Paris. Paris, E. Leroux, 1896. 


\section{7}

- Theunissen $1998=\mathrm{H}$. Theunissen, "Ottoman-Venetian diplomatics: the Ahd-names. The historical background and the development of a category of political-commercial instruments together with an annotated edition of a corpus of relevant documents", Electronic Journal of Oriental Studies, 1-2, 1998, p. 1-698.

- $\quad$ Theunissen $1999=$ H. Theunissen, "Cairo Revisited (I): Four Documents Pertinent to the Ottoman-Venetian Treaty of 1517', Electronic Journal of Oriental Studies, II, 1999, nº 1-29.

- $\quad$ URSU 1908 = J. URSU, La politique orientale de François I (1515-1547), Paris, Honoré Champion, 1908.

- VAtin 1994 = N. VAtin, L'Ordre de Saint-Jean-de-Jérusalem, l'Empire ottoman et la Méditerranée orientale entre les deux sièges de Rhodes 14801522, Louvain-Paris, Peeters, 1994.

- Wansborough $1963=\mathrm{J}$. Wansborough, «A Mamluk ambassador to Venice in $913 / 1507$ », BSOAS, vol. XXIII/3, 1963, p. 503-530.

- Wansborough 1965 = J. Wansborough, «Venice and Florence in the Mamluk commercial privileges », BSOAS, vol. XVIII, 1965, p. 483-523.

- Wansborough 1975 = J. Wansborough, art. « Imtiyāzāt », Encyclopédie de l'Islam, vol. III, 1975, p. 1207-1208. 